\title{
Performance of Various Forms of the Palmer Drought Severity Index in China from 1961 to 2013
}

\author{
ZIQIAN ZHONG AND BIN HE \\ College of Global Change and Earth System Science, Beijing Normal University, Beijing, China \\ LANLAN GUO \\ School of Geography, Beijing Normal University, Beijing, China \\ YAFENG ZHANG \\ College of Global Change and Earth System Science, Beijing Normal University, Beijing, China
}

(Manuscript received 26 November 2018, in final form 3 July 2019)

\begin{abstract}
A topic of ongoing debate on the application of PDSI is whether to use the original version of the PDSI or a self-calibrating form, as well as which method to use for calculating potential evapotranspiration (PET). In this study, the performances of four forms of the PDSI, including the original PDSI based on the PenmanMonteith method for calculating PET $\left(\mathrm{ET}_{p}\right)$, the PDSI based on the crop reference evapotranspiration method for calculating PET ( $\mathrm{ET}_{0}$ ), the self-calibrating PDSI (scPDSI) based on $\mathrm{ET}_{p}$, and the scPDSI based on $\mathrm{ET}_{0}$, were evaluated in China using the normalized difference vegetation index (NDVI), modeled soil moisture anomalies (SMA), and the terrestrial water storage deficit index (WSDI). The interannual variations of all forms of PDSI agreed well with each other and presented a weak increasing trend, suggesting a climate wetting in China from 1961 to 2013. PDSI-ET ${ }_{0}$ correlated more closely with NDVI anomalies, SMA, and WSDI than did PDSI-ET ${ }_{p}$ in northern China, especially in northeastern China, while PDSI-ET ${ }_{p}$ correlated

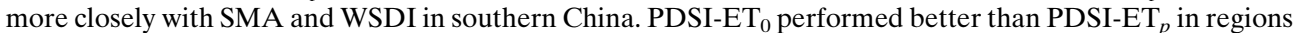
where the annual average rainfall is between 350 and $750 \mathrm{~mm} \mathrm{yr}^{-1}$. The spatial comparability of scPDSI was better than that of PDSI, while the PDSI correlated more closely with NDVI anomalies, SMA, and WSDI than did scPDSI in most regions of China. Knowledge from this study provides important information for the choice of PDSI forms when it is applied for different practices.
\end{abstract}

\section{Introduction}

Drought is a recurring extreme climate event that has devastating effects on regional agriculture, water resources, and the environment (Sheffield et al. 2012). Many types of indices have been developed to evaluate meteorological drought, including the Palmer drought severity index (PDSI; Dai et al. 2004), the standardized precipitation index (SPI), and the standardized precipitation evapotranspiration index (SPEI), etc. PDSI is one of the most commonly used indices to assess drought conditions (Dai 2011a; Hao et al. 2015). The PDSI is first introduced by Palmer (1965) as an agricultural drought monitoring tool in the United States and uses historical records of precipitation and temperature to calculate

\footnotetext{
Corresponding author: Bin He, hebin@bnu.edu.cn
}

surface water balance (Alley 1984). Compared with other popular drought indices (e.g., SPEI), PDSI has a more comprehensive physical mechanism considering the balance of precipitation, evapotranspiration, and runoff and has the ability to assess local soil water and possibly vegetation properties (Trenberth et al. 2014). This can be supported by strong correlations between PDSI and observed streamflow and measured soil reported in the previous study (Dai et al. 2004; Dai 2011a).

The PDSI has gained wide acceptance but has also received criticisms over the years. One primary deficit is that the climatic characteristic $(K)$ and the duration factors $(p$ and $q$ ) were empirically derived in the United States and may not apply to other regions (Akinremi et al. 1996; Vicenteserrano et al. 2014). This shortcoming is partly resolved by devising the self-calibrating Palmer 
drought severity index (scPDSI; Wells et al. 2004). In the scPDSI, the fixed coefficient is replaced by local conditions in order to calibrate the PDSI. The scPDSI has performed better than the PDSI in study areas in Europe and North America (Schrier et al. 2006; van der Schrier et al. 2006). Another important shortcoming is that the PDSI and scPDSI have fixed temporal scales, whereas drought may occur simultaneously across multiple temporal scales (McKee et al. 1993). As a result, the PDSI cannot identify droughts on time scales shorter than 12 months (Vicenteserrano et al. 2010). For example, scPDSI is found to be only suitable for evaluating midterm and long-term term droughts in China, because it is insensitive to short-term drought (H. Zhao et al. 2017). A systematic comparison between PDSI and scPDSI at a national scale is needed before these indices can be applied as detectors of drought in China.

Another main concern with PDSI is the choice of method used to estimate potential evapotranspiration (PET), which is a key variable in PDSI's water balance model. The Thornthwaite PET method (PET_th), which is driven by temperature and latitude (Thornthwaite 1948), is used to simulate PET in the original PDSI model. However, it has been suggested to produce errors in energy-limited regions and overestimate the impact of surface temperature on PET (Hobbins et al. 2008; Sheffield et al. 2012), thereby overestimating drought conditions. Therefore, a fully physically based Penman-Monteith equation PET method (defined as $\mathrm{ET}_{p}$ here), which incorporates the radiative and aerodynamic components that govern the evaporation process, has been recommended to replace the original Thornthwaite method to estimate PET (PET_th) in the PDSI (Sheffield et al. 2012). In recent years, a modified Penman-Monteith equation, the so-called FAO Penman-Monteith equation, which estimates crop reference evapotranspiration ( $\mathrm{ET}_{0}$; Allen et al. 1998), is also frequently used to estimate PET in the PDSI. The main difference between $\mathrm{ET}_{p}$ and $\mathrm{ET}_{0}$ is that they use different hypothetical reference surfaces and therefore have different aerodynamic and surface resistances (McVicar et al. 2005). Previous investigations have suggested that PDSI varies greatly depending on the PET method used. For example, Sheffield et al. (2012) found that the PET_th method overestimated global drought conditions since 1950. Dai (2011a) used both PET_th and $\mathrm{ET}_{p}$ to calculate global PET and suggested that the different PET methods exerted only small effects on both the PDSI and scPDSI. Van der Schrier et al. (2011) also assessed the differences in global PDSI maps using the PET_th or the $\mathrm{ET}_{0}$, and found that, although PET_th and $\mathrm{ET}_{0}$ have very different amplitudes, the PDSI values based on the two PET methods were very similar. Many existing studies have assessed differences between the PDSI and scPDSI indices using the PET_th and $\mathrm{ET}_{p}$ methods or the PET_th and $\mathrm{ET}_{0}$ methods, few of them focused on the differences between the $\mathrm{ET}_{p}$ and $\mathrm{ET}_{0}$ methods when they are used to calculate PDSI, despite the fact that the two methods have large differences in mean value, magnitude, and long-term trends (McVicar et al. 2005).

Using PDSI or scPDSI, drought conditions in China have been extensively studied. Liu et al. (2017) developed a multiscale scPDSI that can monitor droughts along different time scales. Wang et al. (2017) used the scPDSI to investigate changes in drought in China between 1961 and 2009. J. Zhang et al. (2016) assessed drought fluctuations in China (1961-2013) using PDSI based on the PET_th and $\mathrm{ET}_{0}$ methods in order to determine any differences in the responses of these two approaches to global warming. However, few studies have evaluated differences between PDSI and scPDSI when these indices use different PET estimation methods. It is essential to test the performance of a drought index before it is used in a specific region. In this paper, we compared drought estimates in China for the period 1961-2013 given by either the PDSI or the scPDSI with PET estimates based on two different methods. The different drought indicators that were compared included: the original PDSI based on the $\mathrm{ET}_{0}$ method (PDSI-ET ${ }_{0}$ ), the original PDSI based on $\mathrm{ET}_{p}\left(\mathrm{PDSI}_{-\mathrm{ET}}\right)$, the scPDSI based on $\mathrm{ET}_{0}$ (scPDSI-ET ${ }_{0}$ ), and the scPDSI based on $\mathrm{ET}_{p}$ (scPDSI$\left.\mathrm{ET}_{p}\right)$. The performances of various forms of PDSI were evaluated using the normalized difference vegetation index (NDVI) from the Global Inventory Modeling and Mapping Studies (GIMMS) NDVI3g data, the modeled soil moisture anomalies (SMA) from the Global Land Evaporation Amsterdam Model (GLEAM), and the water storage deficit index (WSDI) based on Gravity Recovery and Climate Experiment (GRACE) data.

\section{Study area, data, and methods}

\section{a. Study area and data}

To investigate spatial differences in performance of various forms of the PDSI, China was divided into seven climatic regions based on physical and geographic features (Zhao 1983): the northeast humid/semihumid warm region (NE), the north China humid/semihumid temperate zone (NC), the central and southern China humid subtropical zone (CSC), the south China humid tropical zone (SC), the Inner Mongolia steppe zone (IM), the northwest desert area (NW), and the Qinghai-Tibetan Plateau (QT), as shown in Fig. 1. 


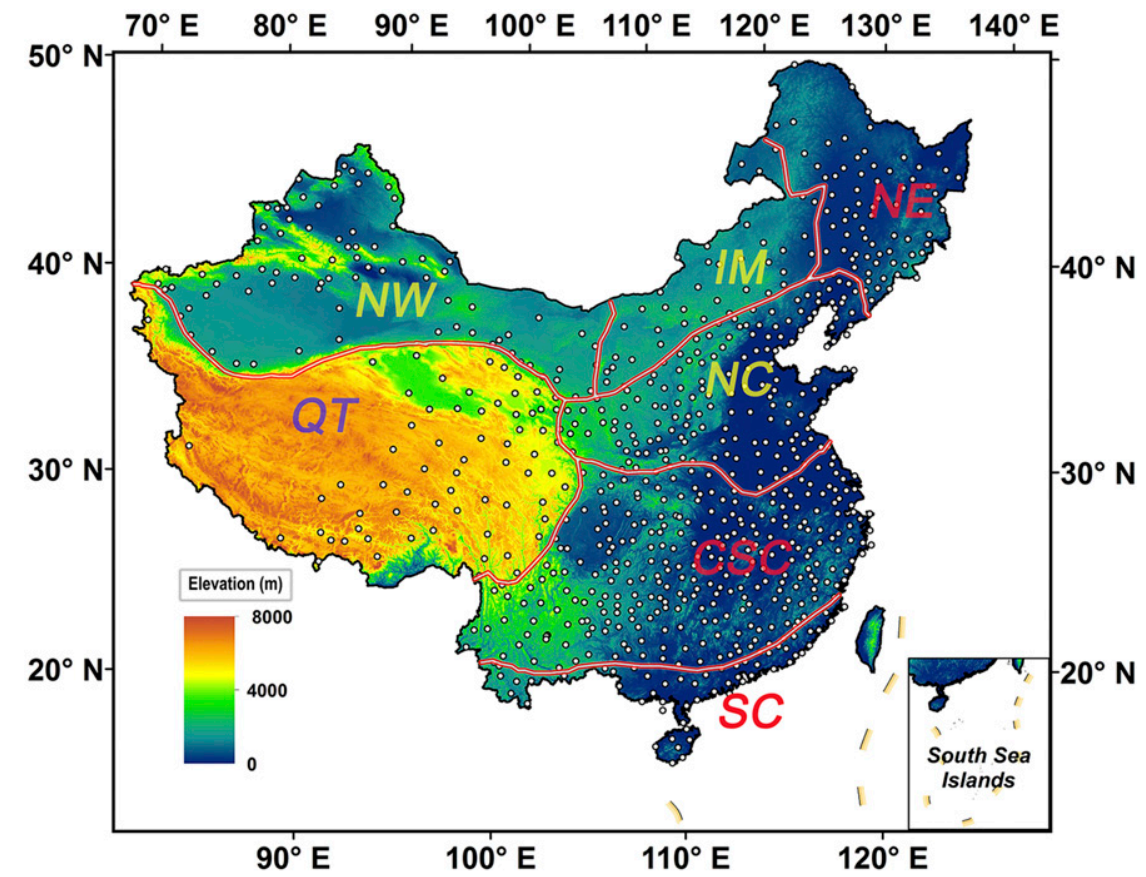

FIG. 1. Locations of the meteorological stations (white dots) included in this study and the seven climatic regions: the northeast humid/semihumid warm region (NE), the north China humid/semihumid temperate zone (NC), the central and southern China humid subtropical zones (CSC), the south China humid tropical zone (SC), the Inner Mongolia steppe zone (IM), the northwest desert area (NW), and the Qinghai-Tibetan Plateau (QT).

Daily meteorological data from 824 stations was provided by the National Meteorological Information Center of the China Meteorological Administration (CMA) (http://data.cma.cn/site/). This dataset includes records of daily precipitation $(P)$, maximum temperature $\left(T_{\max }\right)$, minimum temperature $\left(T_{\min }\right)$, wind speed $(U)$, relative humidity $(\mathrm{RH})$, and sunlight duration (SD). The reliability of the daily meteorological data had been confirmed by the CMA before it was released. Stations with data missing more than $5 \%$ were excluded from this analysis. Finally, a total of 755 stations with relatively complete records from 1961 to 2013 were selected for analysis. To calculate monthly values for the PDSI and scPDSI, the daily meteorological data were aggregated into monthly values.

Datasets of surface vegetation, SMA and total terrestrial water storage were collected to assess the performance of the various forms of PDSI. Satellite-based NDVI was used to indicate vegetation condition. Biweekly GIMMS NDVI3g data $\left(0.083^{\circ}\right.$ latitude $\times 0.083^{\circ}$ longitude grid monthly data) from 1982 to 2013 were obtained from https://ecocast.arc.nasa.gov/data/pub/gimms/ 3g.v1/. Daily root-zone soil moisture (SM) data with a spatial resolution of $0.25^{\circ}$ latitude $\times 0.25^{\circ}$ longitude between 1981 and 2013 were obtained from the Global Land Evaporation Amsterdam Model (GLEAM) Version 3.2 product (https://www.gleam.eu/). The NDVI and SM of each station were extracted from the grid data within the same location. Monthly total terrestrial water storage (TWS) derived from GRACE (RL05) between 2003 and 2013 was provided by the Center for Space Research (CSR) at the University of Texas at Austin, which is presented as $1^{\circ}$ latitude $\times 1^{\circ}$ longitude grid monthly data. The soil properties data were extracted from Harmonized World Soil Database (Nachtergaele et al. 2010) published by the Food and Agriculture Organization of the United Nations (FAO) and the International Institute for Applied Systems Analysis (IIASA). Land cover with 30-m resolution of China was extracted from the Finer Resolution Observation and Monitoring of Global Land Cover (FROM-GLC) issued by Department of Earth System Science, Tsinghua University (http://data.ess.tsinghua.edu.cn/).

\section{b. Methods}

\section{1) A BRIEF OVERVIEW OF PDSI AND SCPDSI CALCULATIONS}

PDSI is one of the indices to quantify the sverity of droughts across different climates, which is based on a water balance model instead of purely precipitation or evaporation. Palmer (1965) describes how to calculate 

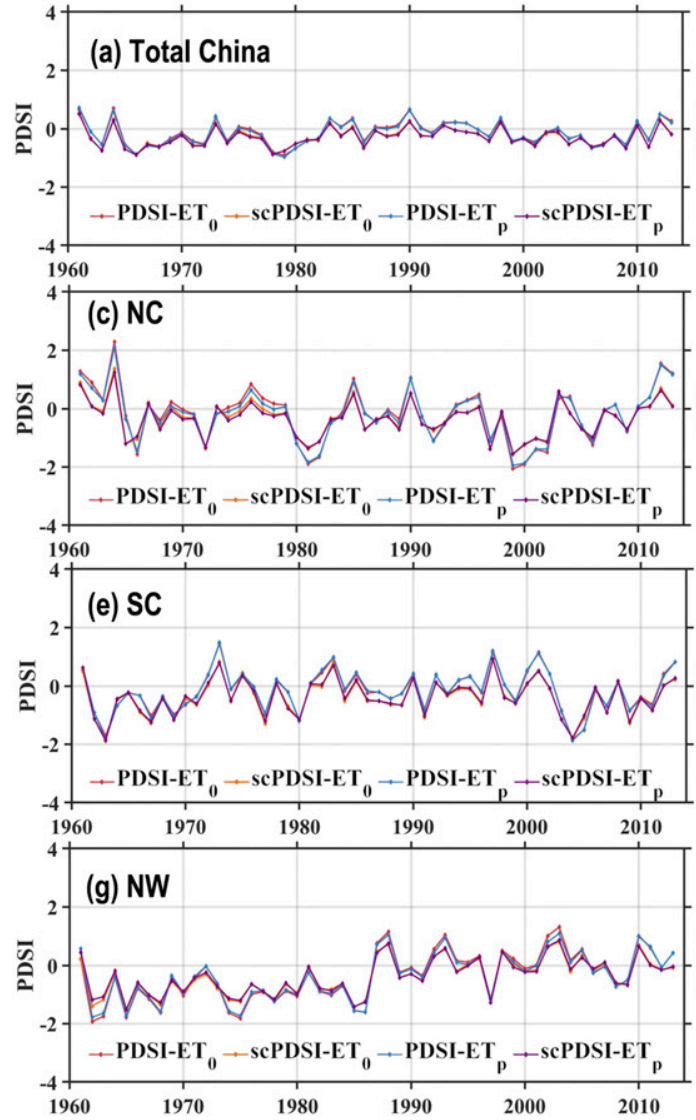
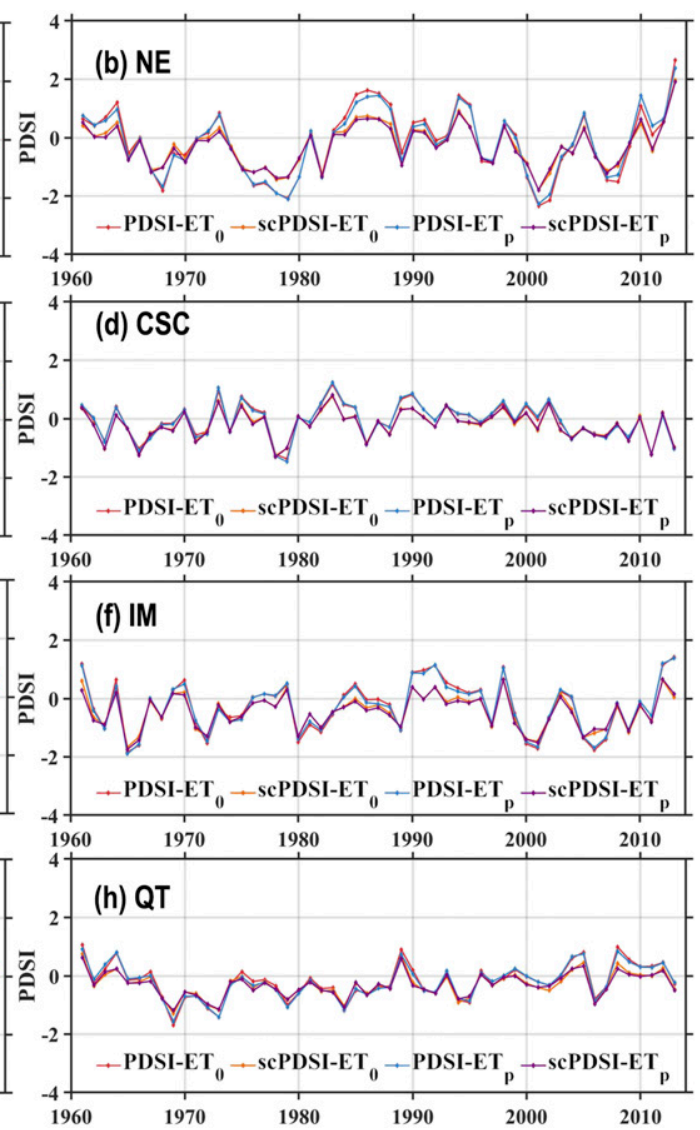

FIG. 2. Interannual variations for different forms of PDSI in (a) the whole of China, (b) NE, (c) NC, (d) CSC, (e) SC, (f) IM, (g) NW, and (h) QT from 1961 to 2013.

the PDSI using monthly data. Eight variables including evapotranspiration $(E)$, recharge to soils $(R)$, runoff (RO), water loss to the soil layers $(L)$, potential evapotranspiration $(\mathrm{PE})$, potential recharge $(\mathrm{PR})$, potential runoff (PRO), and potential loss (PL) during each month were considered. Because the weighting calibration parameter of the original PDSI was empirically derived from limited data from the United States (Palmer 1965), it may not be applicable to other climatic regions. To improve the poor spatial comparability of the original PDSI, Wells et al. (2004) modify the selfcalibration duration factors ( $p$ and $q$ ) and the climatic characteristics $(K)$ based solely on how the climate of the location. Compared with the PDSI, the scPDSI has more comparable frequency distribution across different locations (Dai 2011a). The calculations of PDSI and scPDSI followed the studies of Jacobi et al. (2013) and Wells et al. (2004), respectively.

\section{2) Calculation of PET}

Potential evapotranspiration is the key variable needed to estimate the amount of "climatically appropriate for existing conditions" (CAFEC) precipitation. Differences in how PET_th and $\mathrm{ET}_{p}$ drive PDSI have been extensively examined. Therefore, this study focused on comparisons of PDSI and scPDSI based on $\mathrm{ET}_{0}$ and $\mathrm{ET}_{p}$.

Following Allen et al. (1998), the $\mathrm{ET}_{0}$ model is given by

$$
\mathrm{ET}_{0}=\frac{0.408 \Delta(\mathrm{Rn}-G)+\gamma \frac{900}{T+273.3} U_{2} D}{\Delta+\gamma\left(1+0.34 U_{2}\right)},
$$

where $\Delta\left(\mathrm{kPa}^{\circ} \mathrm{C}^{-1}\right)$ is the slope of the saturation vapor pressure; $\mathrm{Rn}\left(\mathrm{MJ} \mathrm{m}^{-2}\right.$ day $\left.^{-1}\right)$ is net radiation at the ground surface (Yin et al. 2008); $G$ $\left(\mathrm{MJ} \mathrm{m}^{-2}\right.$ day $\left.^{-1}\right)$ is the ground heat flux; $T=\left(T_{\max }+\right.$ $\left.T_{\min }\right) / 2$ is the mean of the daily maximum and minimum air temperatures; $\gamma\left(\mathrm{kPa}^{\circ} \mathrm{C}^{-1}\right)$ is the psychrometric constant; $U_{2}\left(\mathrm{~m} \mathrm{~s}^{-1}\right)$ is the average wind speed at $2 \mathrm{~m}$ above the ground surface, and $D(=$ es - ea) is the saturation vapor pressure deficit, where es $(\mathrm{kPa})$ is the saturation vapor pressure and ea $(\mathrm{kPa})$ is the actual vapor pressure. 


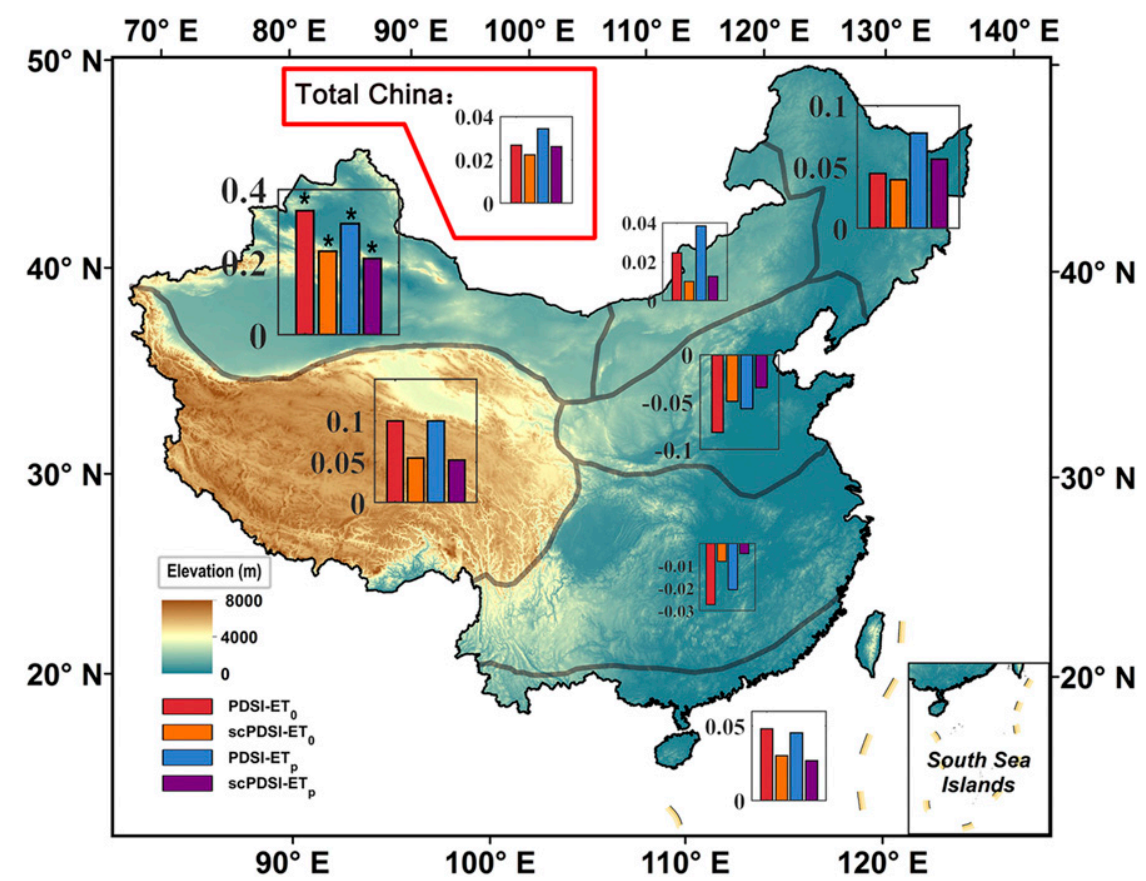

FIG. 3. The slopes (per decade) of trend lines of various forms of PDSI (Fig. 2) in seven regions in China for the period 1961-2013. Bars with an asterisk indicate $p<0.05$.

Following (Penman 1948; Shuttleworth 1993; Valiantzas 2013), $\mathrm{ET}_{p}$ was calculated as

$$
\mathrm{ET}_{p}=\frac{\Delta}{\Delta+\gamma} \mathrm{Rn}+\frac{\gamma}{\Delta+\gamma} \frac{6.43\left(1+0.536 U_{2}\right) D}{\lambda}
$$

where $\lambda$ is the latent heat of vaporization of water $2.45\left(\mathrm{MJ} \mathrm{kg}^{-1}\right)$ and other climatic factors and other parameters are the same as those in Eq. (1).

\section{3) Calculation of WSDI}

WSDI is a GRACE TWS-based drought indicator. Following Sinha et al. (2017), the WSDI was given by

$$
\begin{aligned}
\mathrm{WSDI}_{i} & =\frac{T_{i}^{\mathrm{res}}-\mu_{T}^{\mathrm{res}}}{\sigma_{T}^{\mathrm{res}}}, \\
T_{i}^{\mathrm{res}} & =\mathrm{TWSA}_{i}-\mathrm{TWSA}_{j}^{\mathrm{clim}},
\end{aligned}
$$

where $T$ is the residual time series and $\mu$ and $\sigma$ are the mean and standard deviation of the time series, respectively. The superscripts "res" and "clim" denote residual and mean monthly climatology of the terrestrial water storage anomaly (TWSA). Here, negative residuals indicate deficits in TWS compared to its climatologic mean, whereas positive residuals signify surplus water storage. Variable $i$ is the total number of months in the study period and $j$ varies from 1 to 12 , representing the corresponding calendar month.

\section{4) TREND ANALYSIS}

The Mann-Kendall trend test (Mann 1945; Kendall 1948) was used to determine trends in PDSI and scPDSI in this study. It is a frequently used method for testing trends in climatic and hydrological series without requiring normality or linearity and is also highly recommended by the World Meteorological Organization.

\section{Results}

\section{a. Drought in China}

\section{1) PDSI AND SCPDSI TREND IN CHINA}

We first examined the trends of PDSI-ET ${ }_{p}$, PDSI$\mathrm{ET}_{0}, \mathrm{scPDSI}_{-\mathrm{ET}_{p}}$, and scPDSI-ET $\mathrm{T}_{0}$ at both national and regional scales. Figure 2a shows interannual variations in mean PDSI-ET ${ }_{p}$, PDSI-ET $_{0}$, scPDSI-ET $_{p}$, and scPDSI-ET ${ }_{0}$ in China from 1961 to 2013. The four indices all demonstrated a weak increasing trend, indicating a wetting condition over China. The interannual changes identified by the four forms of the PDSI were similar, although with different trend line slopes (Fig. 3). The largest increase was observed for PDSI-ET $_{p}\left(0.034\right.$ decade $\left.^{-1}\right)$, followed by PDSI-ET 0 $\left(0.026\right.$ decade $\left.^{-1}\right)$, scPDSI-ET $_{p}\left(0.026\right.$ decade $\left.^{-1}\right)$, and scPDSI-ET $_{0}\left(0.022 \mathrm{decade}^{-1}\right)$. At the regional scale, increasing trends of the various forms of PDSI were 

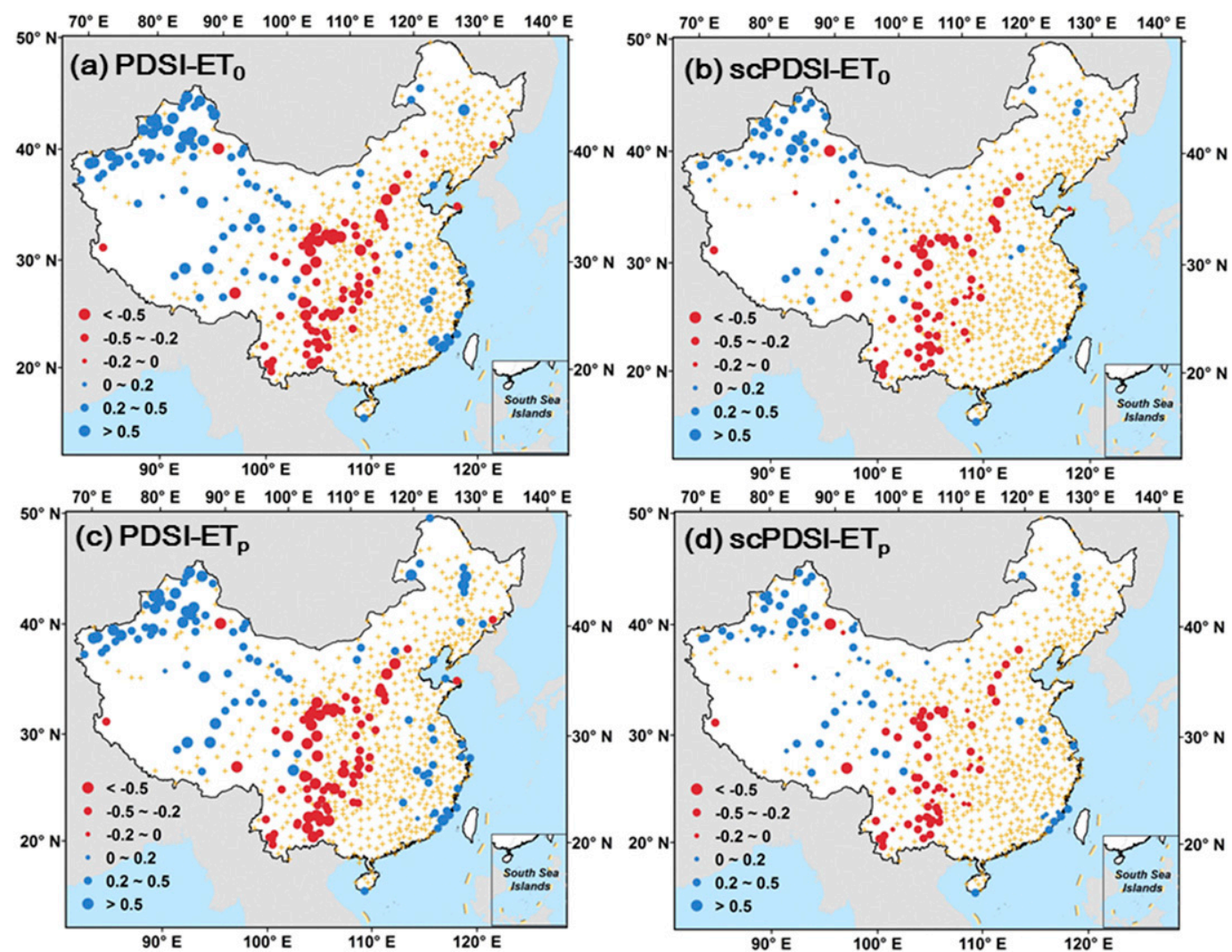

FIG. 4. The slopes of trend lines (per decade) for (a) annual PDSI-ET , $^{\text {, b }) \text { annual scPDSI-ET }}$, (c) annual PDSI$\mathrm{ET}_{p}$, and (d) annual scPDSI-ET $p$ at 755 stations during the period 1961-2013.

observed in NE, NW, SC, QT, and IM, suggesting a climate wetting in these regions. In NW, all forms of PDSI increased significantly $(p<0.05)$ while the ascending trends of PDSI were greater than those for scPDSI. All four PDSI forms showed a decreasing trend in the $\mathrm{NC}$ and CSC regions, indicating a drying climate. PDSI or scPDSI based on $\mathrm{ET}_{0}$ produced larger decreases than those based on $\mathrm{ET}_{p}$. This highlights the influence of PDSI form on determinations of drought conditions.

A relatively uniform spatial pattern (Fig. 4) is observed in the annual trends of all four PDSI forms. At station scale, the majority of the meteorological stations in northwestern China experienced significant increasing PDSI trends, suggesting climate wetting. In contrast, stations in central and south-central China showed significant decreasing trends, indicating drying conditions. The PDSI-ET ${ }_{p}$ produced a greater number of statistically significant positive trends than the other three forms, and a total of 139 stations were identified as having significant trends. PDSI-ET ${ }_{0}$ suggested a total of 120 stations that experienced significant wetting, followed by scPDSI-ET ${ }_{p}$ (102 stations) and scPDSI$\mathrm{ET}_{p}$ (98 stations). PDSI-ET 0 indicated a total of 92 stations that experienced significant drying, followed by $\operatorname{PDSI}^{-E T}{ }_{p}$ (88 stations), scPDSI-ET $_{p}$ (84 stations), and scPDSI-ET ${ }_{0}$ (80 stations).

To reveal the potential reasons for the different trends of four forms of PDSI, we evaluated the trends of two major components of PDSI: precipitation $P$ and actual evapotranspiration $E$ estimated by the Palmer model. Here, $E$ was evaluated because it has a greater effect on the PDSI model than PET (Dai 2011a). As shown in Fig. 5, the average annual $P$ did not change significantly over the whole of China during 1961-2013. However, two forms of actual evapotranspiration, namely evapotranspiration estimated by the Palmer model based on $\mathrm{ET}_{0}\left(E_{0}\right)$ and $\mathrm{ET}_{p}\left(E_{p}\right)$, respectively, decreased significantly $(P=0.1)$ between 1961 and 2013. The annual mean $E_{p}\left(-0.31 \mathrm{yr}^{-1}\right)$ decreased faster than annual mean $E_{0}\left(-0.29 \mathrm{yr}^{-1}\right)$ in China. This may explain why PDSI or scPDSI based on $\mathrm{ET}_{p}$ produce more significant wetting trends or less significant drying trends than those based on $\mathrm{ET}_{0}$ in China. In the NW of China, the story was different. Both of $E_{0}$ and $E_{p}$ in this region showed an insignificant increasing trend ( $p=0.31$ of the trend of $E_{0}$ and $p=0.36$ of the trend of $\left.E_{p}\right)$, while the increasing trend of $P$ was relatively striking $(p=0.13$ ), which finally caused a climate wetting in this region. 

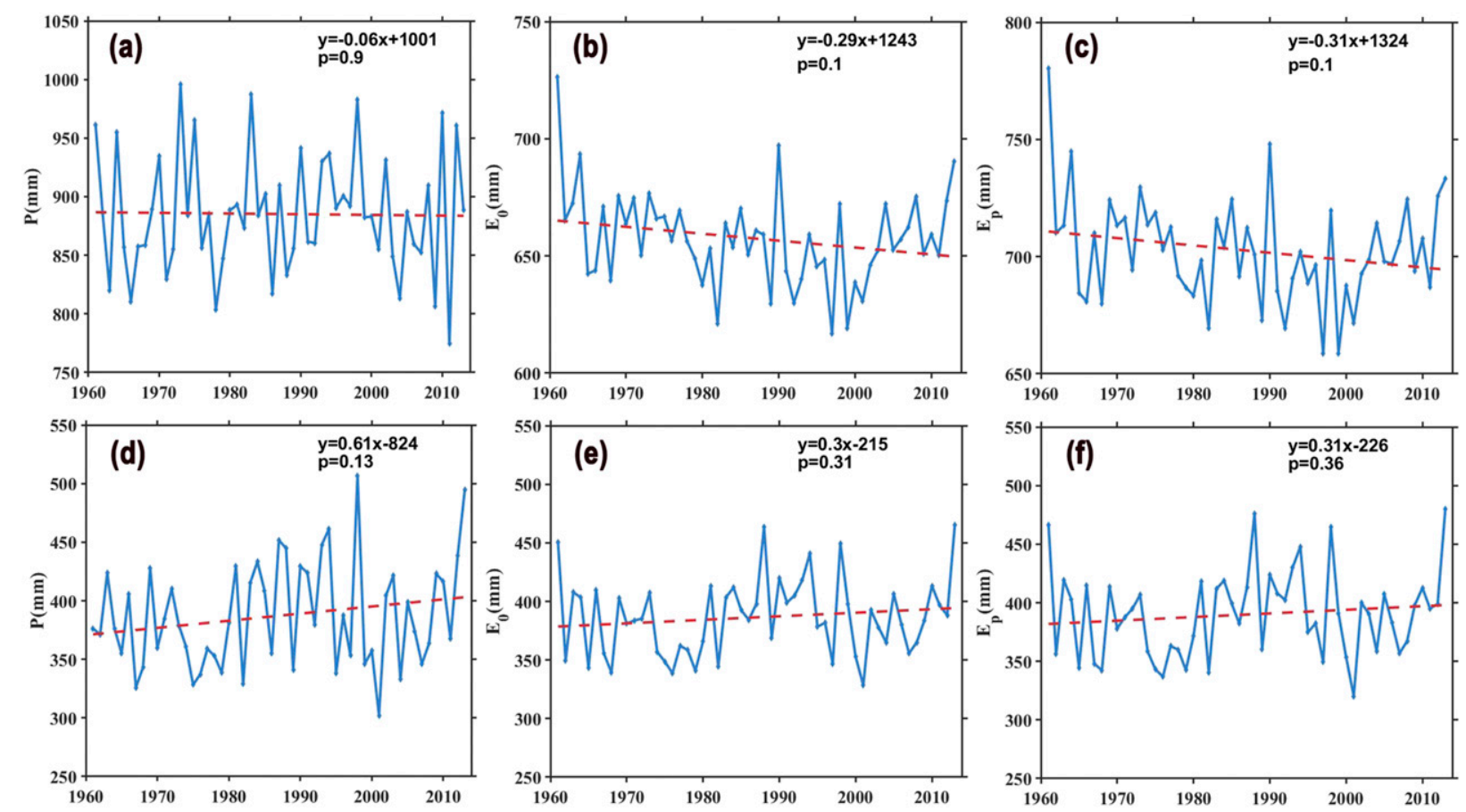

FIG. 5. Interannual variations of (a) annual $P$, (b) annual $E_{0}$, and (c) annual $E_{p}$ in the whole of China and (d) annual $P$, (e) annual $E_{0}$, and (f) annual $E_{p}$ in the NW from 1961 to 2013.

The above analysis suggested that the choice of PDSI form had only a small influence on the identification of long-term trend for the whole of China. However, different PDSI forms could produce different trend slopes at regional and station scales. The PDSI tended to generate larger trend line slopes than scPDSI, and PDSI and scPDSI based on $\mathrm{ET}_{0}$ produced larger "drying" trend than that based on $\mathrm{ET}_{p}$ because the decrease of $E_{p}$ was faster than that of $E_{0}$ in China.

\section{2) SEVERE DROUght FREQUeNCY IN CHINA}

To better understand drought conditions in China and further distinguish the performance of different forms of PDSI, the frequency of severe drought in China during 1961-2013 was investigated. The frequency of severe drought is defined as the percentage of months when the PDSI is less than -3 . Figure 6 shows the difference between the severe drought events produced by PDSI and scPDSI based on $\mathrm{ET}_{0}$ and $\mathrm{ET}_{p}$. Assessing by PDSI-ET 0 or $\mathrm{PDSI}_{-\mathrm{ET}_{p}}$, high frequency of severe drought occurred in stations in northeastern, northwestern and southwestern China, while scPDSI seems to produce less severe droughts in above regions. A distinction is made according the difference between severe drought frequency identified by PDSI-ET ${ }_{0}$ and PDSI-ET ${ }_{p}$, respectively, as shown in Fig. 7. Interestingly, during 19612013, PDSI-ET $_{0}$ produced more severe drought events in north China, especially in northeastern China and

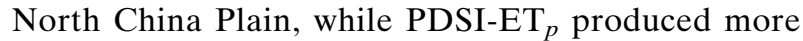
severe drought events in southern China, especially in southwestern China. The above analysis suggests that the choice of PDSI form has great influence on the identification of severe drought events.

\section{b. Evaluation of PDSI and scPDSI}

\section{1) CORRELATION ANALYSIS BETWEEN MONTHLY NDVI AND PDSI}

Droughts are usually associated with depressions of vegetation growth state. A recent study also suggested that vegetation activity is sensitive to drought in northern China, especially in its eastern part (Hua et al. 2017). To further evaluate the PDSI forms via vegetation behaviors in northeastern China, stations in NE, the eastern part of IM, the northern part of NC were selected to examine the response of NDVI during the growing season (from May to September) to the four forms of PDSI. Owing to the differences in grid size between NDVI and PDSI datasets, for each station the NDVI time series were extracted from the nearest grid. Considering the potential delayed response of vegetation growth to drought (Vicenteserrano et al. 2013), for each form of PDSI, the Pearson correlation coefficients were calculated between the growing season monthly NDVI anomalies series and five group of PDSI series, namely, PDSI series from January to May, from February to 

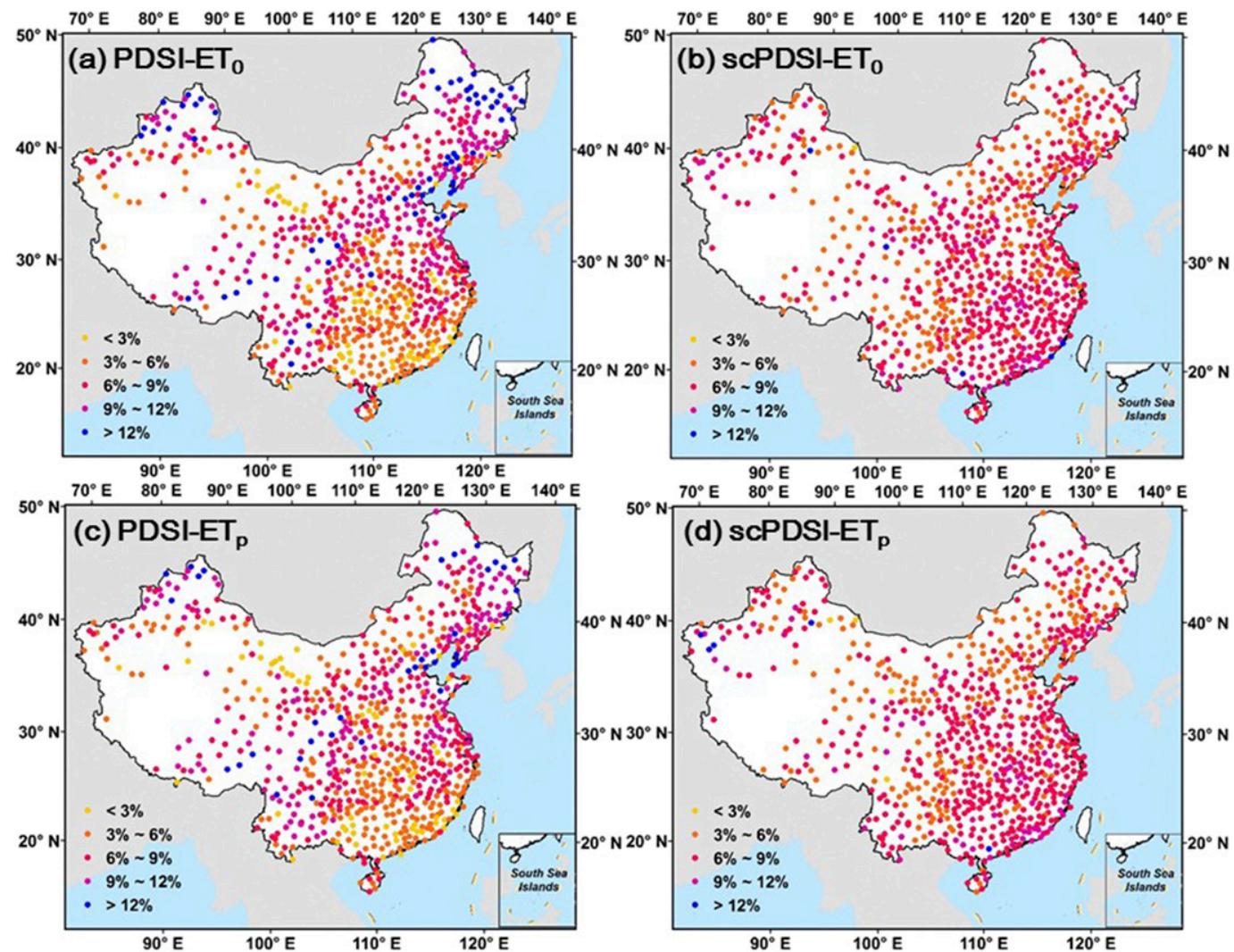

FIG. 6. The frequency of severe droughts (the percentage of months when PDSI $<-3$ ) at 755 stations for the period 1961-2013.

June, from March to July, from April to August, and from May to September, respectively. Then the maximum of these five correlation coefficient (Max CorrelCoeff) was determined to represent the strongest relationship between vegetation activity and this form of PDSI. Total 103 stations with significant correlations $(p<0.05)$ between NDVI and PDSI were remained for the following evaluation.

The correlation coefficients between PDSI and NDVI anomalies at different time lags (0-4 months; Fig. 8) suggested that positive correlation was mostly strong when PDSI preceded NDVI by 1-month in most of region. Figure 9a shows the Max CorrelCoeffs of different forms of PDSI at all 103 stations during the period 19822013. The minimum, first quartile, third quartile, and maximum of the Max CorrelCoeffs group of PDSI-ET ${ }_{0}$ were all largest among four forms of the PDSI, suggesting that the PDSI-ET $\mathrm{P}_{0}$ correlated more closely with the NDVI anomalies than other forms of PDSI in this region. The Max CorrelCoeffs of PDSI or scPDSI with $\mathrm{ET}_{0}$ were larger than those with $\mathrm{ET}_{p}$. Additionally, the Max CorrelCoeffs of PDSI were larger than those of scPDSI during studied period. The spatial pattern of the PDSI forms (Fig. 9b) showed the highest correlations with the NDVI anomalies in the east part of northern China during 1982-2013. Among which, 41 stations showed the largest correlations between NDVI and PDSI-ET $_{0}$, followed by 27 stations for scPDSI-ET ${ }_{0}$,

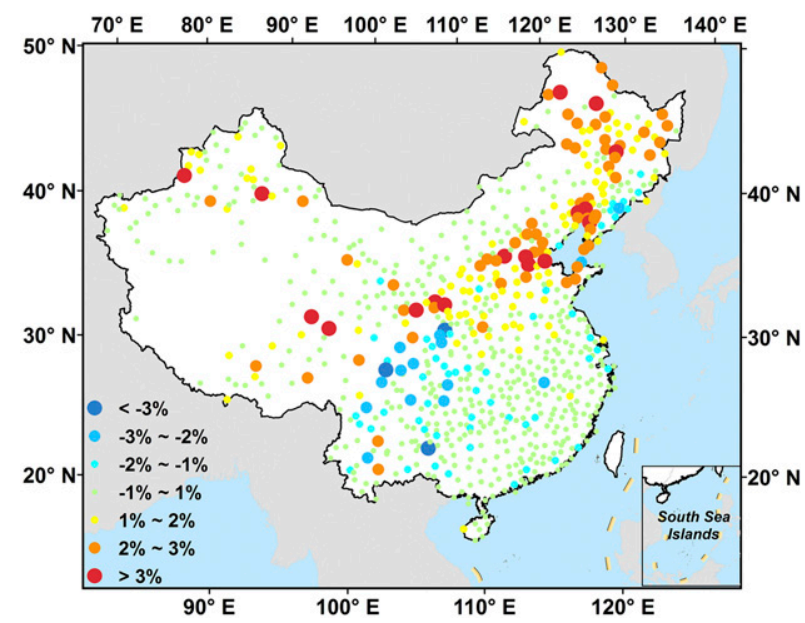

FIG. 7. Differences between frequencies of severe drought identified by PDSI-ET 0 and PDSI-ET , $_{0}$, respectively (the frequency of severe drought suggested by PDSI-ET 0 minus that suggested by PDSI-ET $_{p}$ ), at 755 stations in China for the period 1961-2013. 
(a) PDSI-ET

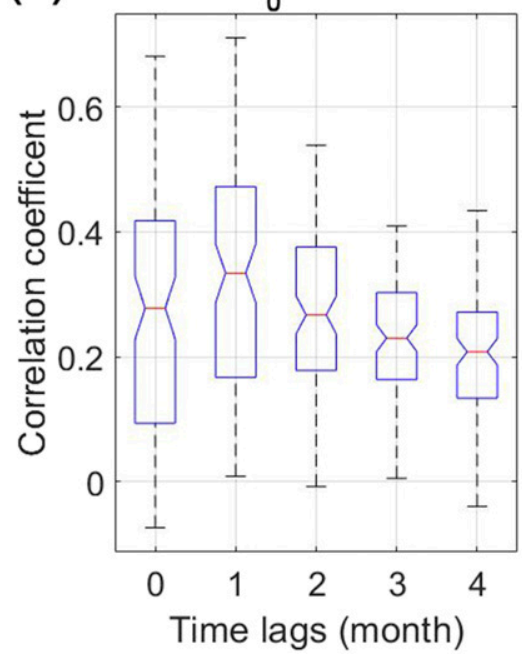

(c) PDSI-ET

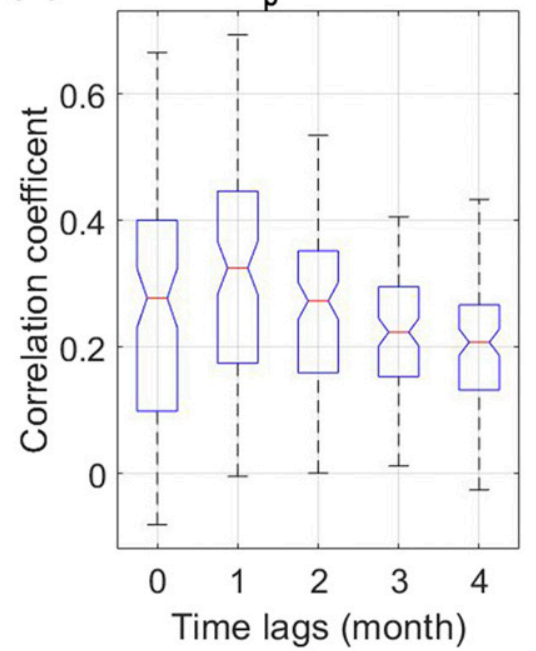

(b) ScPDSI-ET,

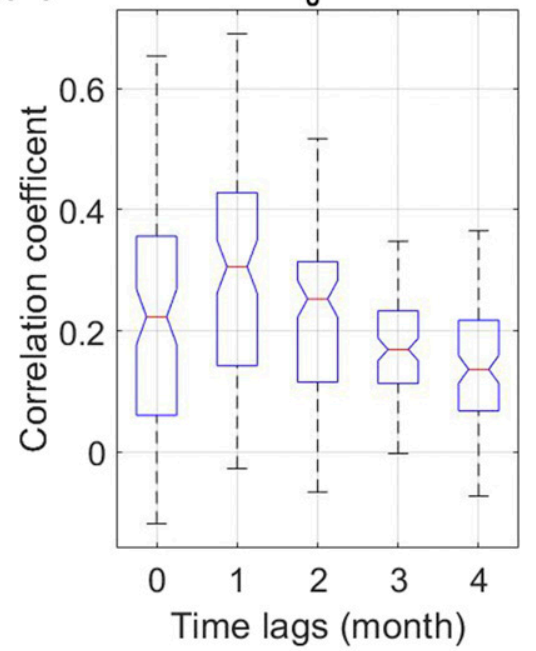

(d) ScPDSI-ET,

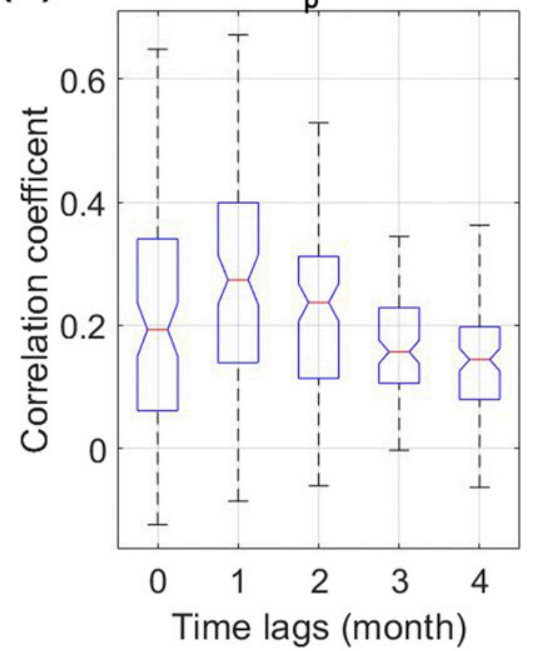

FIG. 8. The boxplot of correlation coefficients between monthly NDVI abnormities and

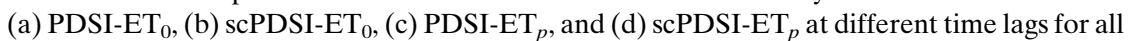
103 stations during 1982-2013.

21 stations for PDSI-ET ${ }_{p}$, and 14 stations for scPDSI$\mathrm{ET}_{p}$. Overall, the PDSI exhibits more closely with NDVI anomalies than scPDSI, whether it was calculated via $\mathrm{ET}_{0}$ or $\mathrm{ET}_{p}$. However, the PDSI or scPDSI based on $\mathrm{ET}_{0}$ showed a higher correlation with NDVI anomalies than did PDSI or scPDSI with $\mathrm{ET}_{p}$.

\section{2) CORRELATION ANALYSIS BETWEEN MONTHLY SMA AND PDSI}

PDSI is typically used as a proxy of SM (Dai 2011b). Hence, SM data from GLEAM was used here to evaluate the performances of the different PDSI forms. For each station, the SM series was extracted from the nearest grid to calculate the monthly anomalies of SM (SMA). The monthly SMA was correlated to four forms of PDSI with 0-3-months lags. The maximum correlations were observed between SMA and all four forms of PDSI at 0-months lag (Fig. 10), indicating a prompt response of SMA to PDSI. Figure 11 shows the spatial patterns of correlations between monthly SMA and the different forms of PDSI in China from 1981 to 2013. The significant relationships $(p<0.05)$ between SMA and all forms of PDSI could be observed for all stations. Relatively weak relationships were scattered in the northwest of China. Compared with scPDSI, the PDSI generally correlated more closely with SMA. To further evaluate the influence of self-calculation process (PDSI$\mathrm{ET}_{0}$ vs scPDSI-ET ${ }_{0}$ ) and different PET models (PDSI$\mathrm{ET}_{0}$ vs PDSI-ET ${ }_{p}$ ), we respectively calculated their correlation coefficient differences with SMA and shown 
(a)

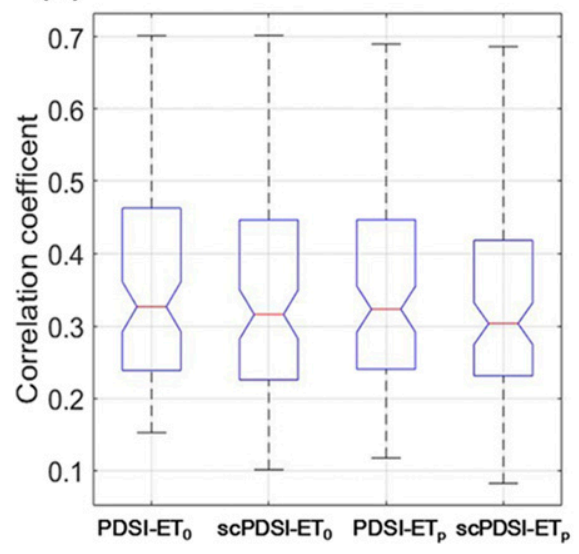

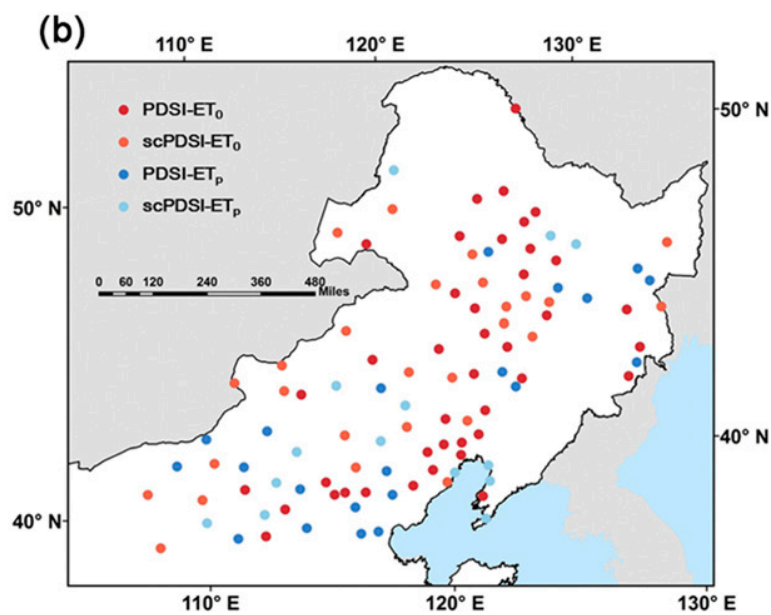

FIG. 9. The maximum correlation coefficients between NDVI abnormities and four forms of PDSI. (a) The boxplot of the maximum correlation coefficients between NDVI and four forms of PDSI for all 103 stations during 1982-2013. The correlation coefficient is higher than 0.15 when $p<0.05$. (b) The spatial pattern of PDSI forms that presented the maximum correlation with NDVI for 103 stations in northeastern China for the period of 1982-2013.

in Fig. 12. Overall, PDSI-ET 0 captured SMA signals better than PDSI-ET $_{p}$ in northern China, especially in northeastern China, the North China Plain, and the east part of Qinghai-Tibetan Plateau, but lost its advantage in southern China, especially in southwestern China. PDSI-ET $_{0}$ also performed better than scPDSI-ET ${ }_{0}$ in most regions, except for limited stations in northwestern China and the lower reaches of the Yangtze River.

Our results suggested that $\mathrm{PDSI}^{-\mathrm{ET}_{p}}$ performed better than PDSI-ET 0 in capturing SMA signals in regions with abundant rainfall. For further inspection, we adopted multiyear average precipitation as an index to testify the performances of PDSI-ET ${ }_{0}$ and PDSI-ET P. $_{\text {. }}$ Figure 13a shows the relationship between annual mean precipitation and the difference between PDSI-ET 0 versus SMA correlation and PDSI-ET $_{p}$ versus SMA correlation at all 755 stations during 1961-2013. We further counted the number of stations in Fig. 13a with an interval of $100 \mathrm{~mm} \mathrm{yr}^{-1}$, as shown in Fig. 13b. Generally, in regions where average rainfall was less than about $300 \mathrm{~mm} \mathrm{yr}^{-1}$ or more than $800 \mathrm{~mm} \mathrm{yr}^{-1}$, the PDSI$\mathrm{ET}_{p}$ correlated more closely with SMA than PDSI-ET 0 . However, a better performance of PDSI-ET P $_{0}$ than PDSI$\mathrm{ET}_{p}$ in capturing SMA was observed in regions with average precipitation between about $350-750 \mathrm{~mm} \mathrm{yr}^{-1}$. Above phenomenon was also supported by the spatial patterns of multiyear mean rainfall and differences between correlation coefficients between SMA and PDSI$\mathrm{ET}_{0}$ and PDSI-ET ${ }_{p}$, respectively, as shown in Fig. 14a. In general, the correlation coefficients between SMA and PDSI-ET $_{0}$ were larger than those between SMA and $\mathrm{PDSI}_{-\mathrm{ET}_{p}}$ in stations where average rainfall is between 400 and $800 \mathrm{~mm} \mathrm{yr}^{-1}$ and the land cover is grassland or cropland (Fig. 14b), while the PDSI-ET ${ }_{p}$ correlated more closely with SMA than PDSI-ET P $_{0}$ in southern China where average rainfall is more than $800 \mathrm{~mm} \mathrm{yr}^{-1}$ and is covered by forests, or in bare land in northwestern China where average rainfall is less than $100 \mathrm{~mm} \mathrm{yr}^{-1}$. Above analysis suggested that the performances of PDSI-ET ${ }_{0}$ and PDSI-ET $p$ are related to local land cover conditions, which are mainly determined by average rainfall.

\section{3) CORRELATION ANALYSIS BETWEEN MONTHLY WSDI AND PDSI}

The TWS-based drought index, WSDI, has been used to compare with commonly used drought indices (Long et al. 2013; D. Zhang et al. 2016). Due to the relative coarse resolution GRACE, the grid WSDI cannot be compared directly with the station PDSI. Therefore, we calculated the correlation between regional mean PDSI across all station in a region and regional mean TWS over all grids of the defined region during 2003-13. The correlation coefficients between PDSI and WSDI at different time lags (0-3 months) (Fig. 15) suggested that positive correlation was mostly strong when PDSI preceded WSDI by $0-1$ months in most of region. Figure 16 exhibits the maximum of correlation coefficients between WSDI and four forms of PDSI in seven regions when time lags were considered. All forms of PDSI showed significant correlation $(p<0.05)$ with WSDI in most regions, except for the PDSI in NC. Relatively large correlations between the different forms of PDSI and the WSDI were found in SC and NE, while relatively small correlations were found in NC and IM. The PDSI-ET ${ }_{0}$ correlated more closely with WSDI than did 
(a) PDSI-ETo

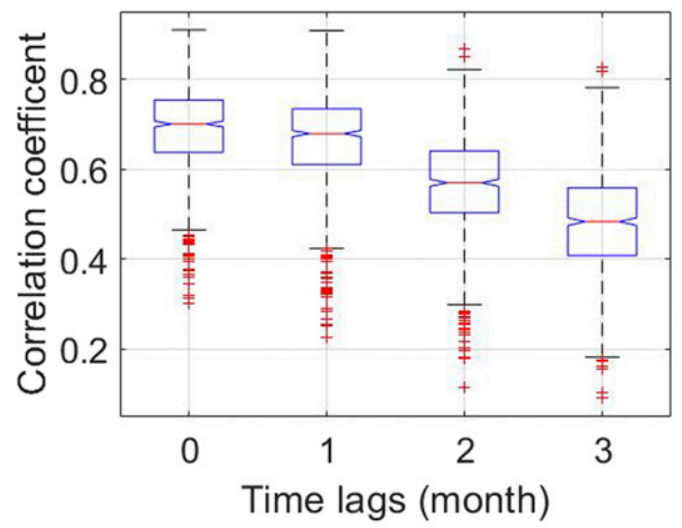

(c) PDSI-ET

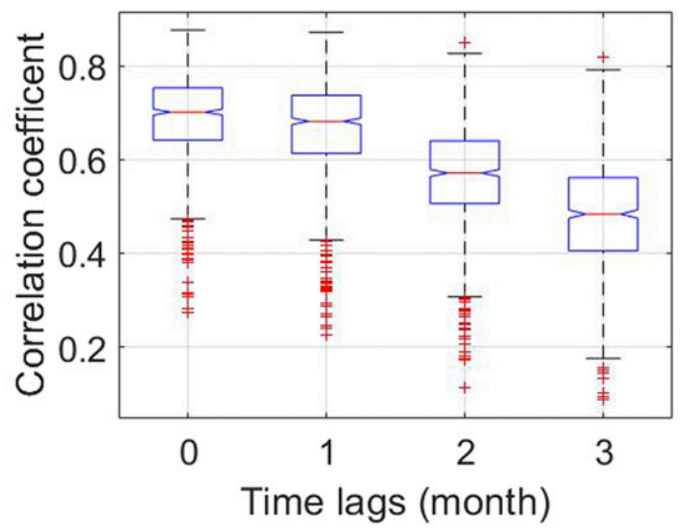

(b) ScPDSI-ET

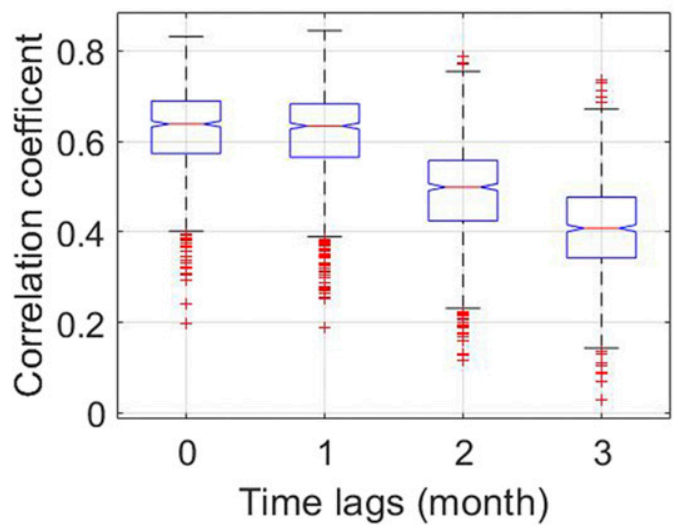

(d) scPDSI-ET

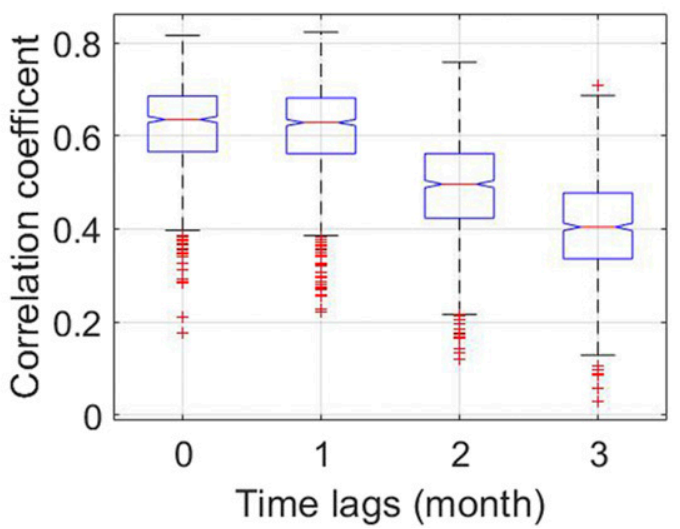

FIG. 10. The boxplot of correlation coefficients between monthly SMA and (a) PDSI-ET 0 , (b) scPDSI-ET , (c) PDSI-ET , and (d) scPDSI-ET $_{p}$ at different time lags for all 755 stations in China for the period 1981-2013.

$\mathrm{PDSI}_{-\mathrm{ET}_{p}}$ in most regions of northern China, especially in NE, where correlation coefficient between PDSI-ET $_{0}$ and WSDI was 0.83 while that between $\mathrm{PDSI}^{-\mathrm{ET}_{p}}$ and WSDI was 0.8 . The correlation between PDSI-ET $_{p}$ and WSDI was higher than that between PDSI-ET ${ }_{0}$ and WSDI in southern China such as CSC. In addition, the correlations between PDSI and WSDI were higher than those between scPDSI and WSDI in most regions except for the NW and $\mathrm{NC}$, where the scPDSI with $\mathrm{ET}_{0}$ or $\mathrm{ET}_{p}$ correlated more closely with WSDI than did the PDSI with $\mathrm{ET}_{0}$ or $\mathrm{ET}_{p}$.

\section{4) THE SPATIAL COMPARABILITY OF PDSI AND SCPDSI}

Previous study suggested that the scPDSI identified far fewer months with extreme drought or wet spells than did by PDSI for same regions (Schrier et al. 2006). Here, the probability distributions of the monthly PDSI-

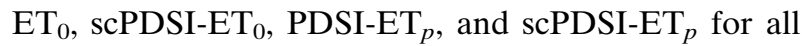

stations in China from 1961 to 2013 were calculated (Fig. 17). Compared with the PDSI calculated by $\mathrm{ET}_{0}$ or $\mathrm{ET}_{p}$, the scPDSI calculated by $\mathrm{ET}_{0}$ or $\mathrm{ET}_{p}$ presented a better near-normal pattern, and the variations in extreme drought or extreme wet spells were controlled at a relative lower level. Figure 18 shows the frequency of extreme wet or dry conditions (the percentage of times that the PDSI was at above 4 or below -4 , respectively) reported by the different forms of PDSI at each station from 1961 to 2013. In short, the scPDSI with $\mathrm{ET}_{0}$ or $\mathrm{ET}_{p}$ producted less extremes than did by PDSI with $\mathrm{ET}_{0}$ or $\mathrm{ET}_{p}$, particularly in NE, NC, IM, and NW of China, suggesting a better spatial comparability of scPDSI than that of PDSI in China.

\section{Discussion}

\section{a. Drought fluctuations in China}

This study compared four forms of PDSI by determining their trends and examining their capacities to 

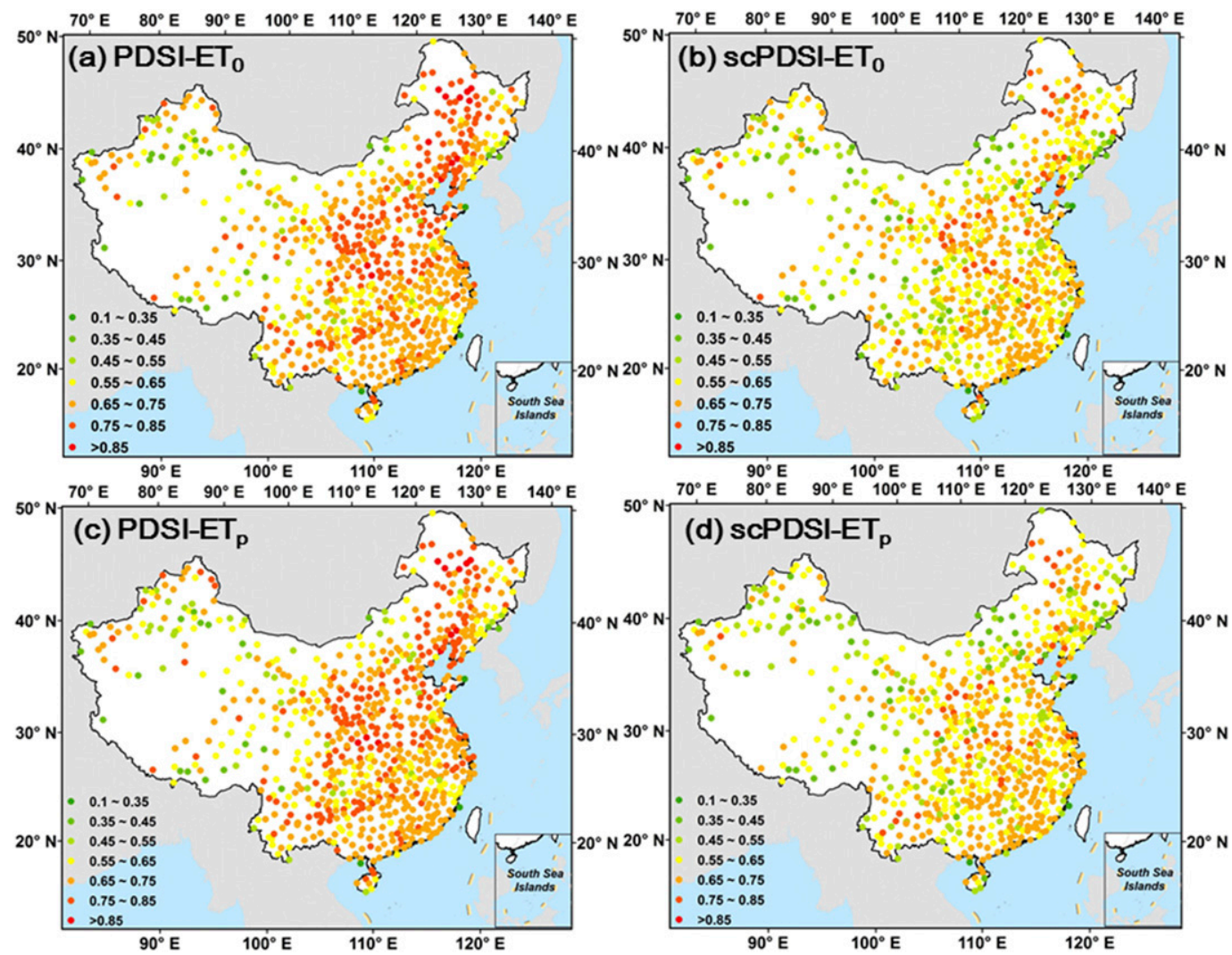

FIG. 11. Spatial distributions of correlation coefficients between monthly SMA and (a) PDSI-ET 0 , (b) scPDSI$\mathrm{ET}_{0}$, (c) PDSI-ET, and (d) scPDSI-ET $p$ at 755 stations for the period of 1981-2013. The correlation coefficient is higher than 0.1 when $p<0.05$.

capture vegetation anomalies, SMA, and TWSA. For China as a whole, all forms of PDSI demonstrated weak increasing trends, suggesting a wetting climate, which is consistent with previous investigations using drought indices (PDSI, SPEI) based on $\mathrm{ET}_{0}$ or $\mathrm{ET}_{p}$, but is inconsistent with studies using drought indices based on PET_th. It has been suggested that the PET_th method overestimates the impact of temperature on PET

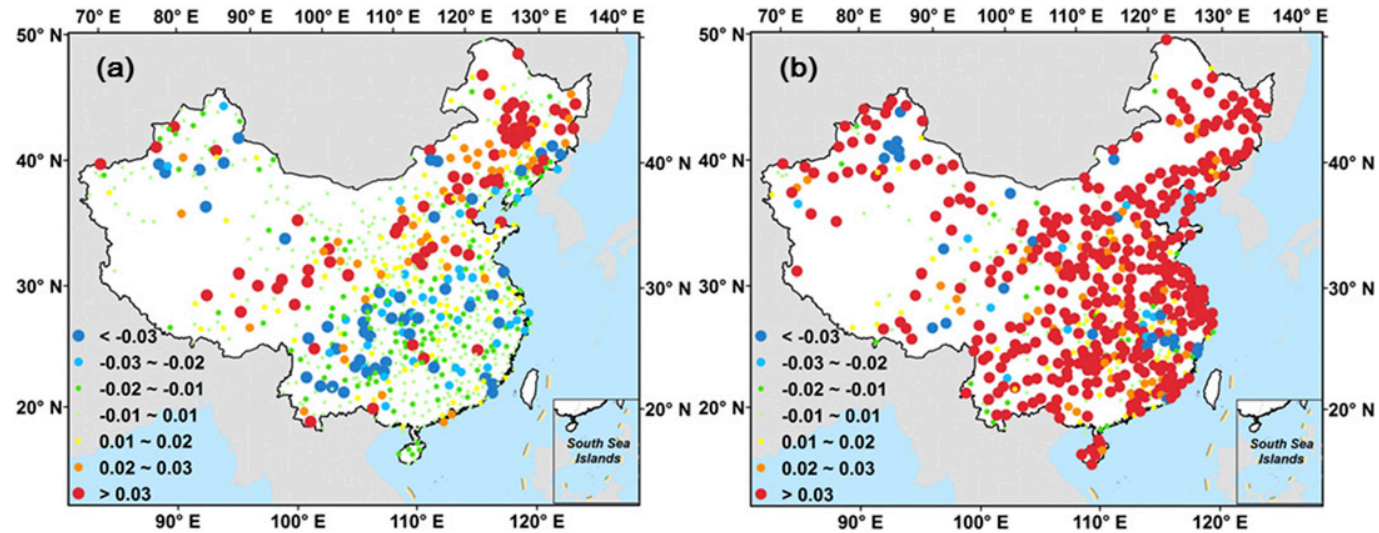

FIG. 12. Differences in the correlation coefficients (a) between SMA and PDSI-ET ${ }_{0} / \mathrm{PDSI} \mathrm{ET}_{p}$ (coefficient between SMA and PDSI-ET - coefficient between SMA and PDSI-ET $_{p}$ ) and (b) between SMA and PDSI-ET $/$ scPDSI-ET $_{0}$

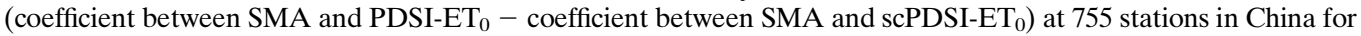
the period of 1981-2013. 

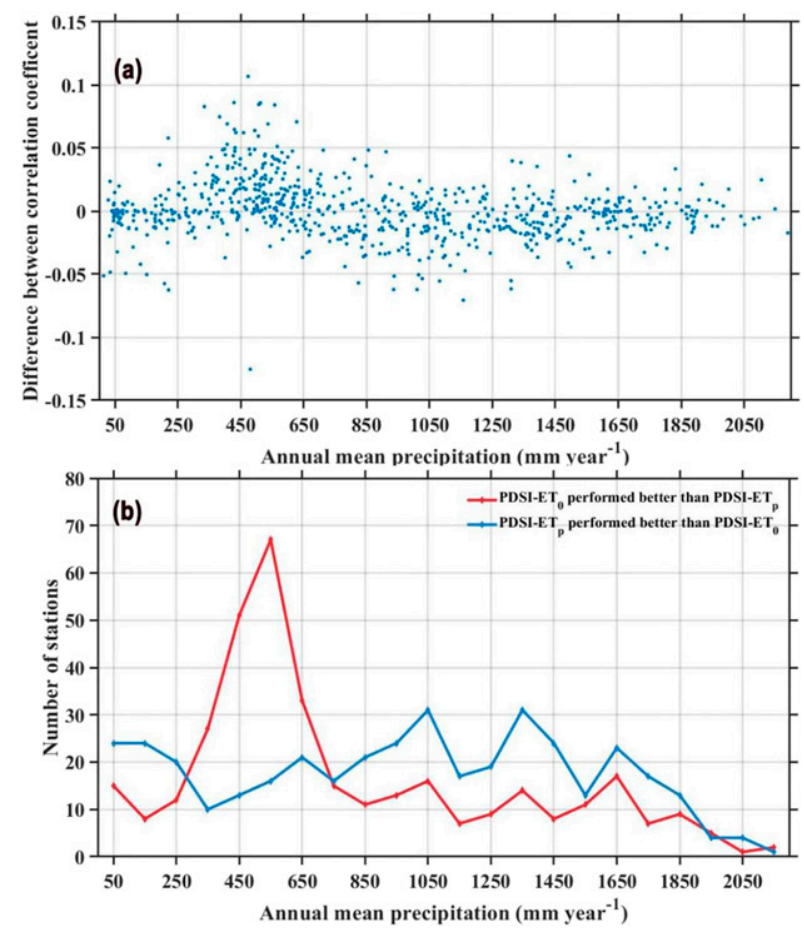

FIG. 13. The relationship between multiyear average precipitation and the performances of PDSI-ET PO PDSI-ET $_{p}$. (a) The relationship between annual mean precipitation and the difference between PDSI-ET V $_{0}$ sMA correlation coefficient and PDSI-ET $_{p}$ vs SMA correlation coefficient (PDSI-ET V $_{0}$ SMA correlation PDSI-ET $_{p}$ vs SMA correlation) for all 755 stations in China, and (b) the relationship between annual mean precipitation and the number of stations with a better performance of PDSI-ET PI $_{0}$ than PDSI-ET $_{p}\left(\right.$ PDSI-ET $_{0}$ vs SMA correlation $>$ PDSI-ET $_{p}$ vs SMA correlation) or the opposite condition.

(Hobbins et al. 2008) and therefore overestimates drought conditions in the context of global warming. PET calculations that use the Penmen-type equation, however, are less affected by temperature, and consider influences from other climatic factors such as surface radiation (Roderick et al. 2007), wind speed (McVicar et al. 2012), and humidity deficit (Zhang et al. 2015). J. Zhang et al. (2016) compared the sensitivity of PDSI to $\mathrm{ET}_{0}$ and PET_th and found that the PET_th-based PDSI overestimated drought conditions due to its high sensitivity to warming and thereby suggested a drying trend over China from 1961 to 2013, while PDSI-ET 0 indicated a weak wetting trend over China. These contradictory conclusions were also reflected in studies by $\mathrm{Yu}$ et al. (2014) and Wang et al. (2017), who both used the SPEI to study drought conditions in China, but used different PET forms: the former was based on PET_th and the latter was based on $\mathrm{ET}_{p}$. Chen and Sun (2015) also suggested that the SPEI based on PET_th overestimates drought conditions in China, especially in the north and northwest. Our study found that the northwest and the Qinghai-Tibetan Plateau regions of China experienced significant wetting trends, which was also reported by previous studies (Chen and Sun 2015; Wang et al. 2015; Wang et al. 2017). In our study, the nationally insignificant wetting trend can be largely explained by the decline of evaporation in most regions as the small change of precipitation, which could be proved indirectly by the decreased pan evaporation in China over the past decades (Liu et al. 2010; Liu et al. 2011). However, the significant wetting trend in NW is mainly caused by the increased precipitation, which has been reported by previous studies ( $\mathrm{Li}$ et al. 2012, 2013). In addition, we identified a dry trend in central and south-central China, which was also roughly consistent with previous studies (Chen and Sun 2015; Wang et al. 2017). The main cause may be the decreased precipitation ( $\mathrm{Wu}$ et al. 2016) and warming associated increase of evaporation (Chu et al. 2015).

\section{b. Influence of different PET calculation methods on PDSI}

Potential evapotranspiration is an important forcing factor needed to estimate the amount of precipitation required under CAFEC. In this study, we used two different methods to calculate PET: $\mathrm{ET}_{0}$ and $\mathrm{ET}_{p}$, which have been widely used in previous studies (Dai 2011a; van der Schrier et al. 2011; J. Zhang et al. 2016). Although both the $\mathrm{ET}_{0}$ and $\mathrm{ET}_{p}$ methods can evaluate evaporative processes in terms of atmospheric water demand, they are not equivalent terms. Differences in $\mathrm{ET}_{0}$ and $\mathrm{ET}_{p}$ have been described by (Dodds et al. 2005; McVicar et al. 2005; McVicar et al. 2012) in detail. In short, the differences include 1) The surface resistance (rs) of $\mathrm{ET}_{0}$ has a prescribed value of $70 \mathrm{~s} \mathrm{~m}^{-1}$ (Allen et al. 1998), while rs of $\mathrm{ET}_{p}$ is $0 \mathrm{~s} \mathrm{~m}^{-1}$, and 2) different assumptions of underlying surface conditions. The assumptions of underlying surface condition of $\mathrm{ET}_{0}$ is "grass with an assumed crop height of $0.12 \mathrm{~m}$, a fixed surface resistance of $70 \mathrm{~s} \mathrm{~m}^{-1}$, and an albedo of 0.23 " (Allen et al. 1998), while the surface condition of $\mathrm{ET}_{p}$ is "a short green crop, completely shading the ground, of uniform height and with adequate water status in the soil profile" (Penman 1948, 1963), which is wider than that of $\mathrm{ET}_{0}$ because there are more types of horticultural and agronomic crops that fit into the description of Xu et al. (2006). The differences between $\mathrm{ET}_{p}$ and $\mathrm{ET}_{0}$ are directly reflected in their mean values and ultimate PDSI values and trends, as observed in this study. Moreover, the choice of PET has great influence on the identification of severely drought events. PDSI-ET ${ }_{0}$ reported more severe drought events in north China while PDSI$\mathrm{ET}_{p}$ identified more severe drought events in south 


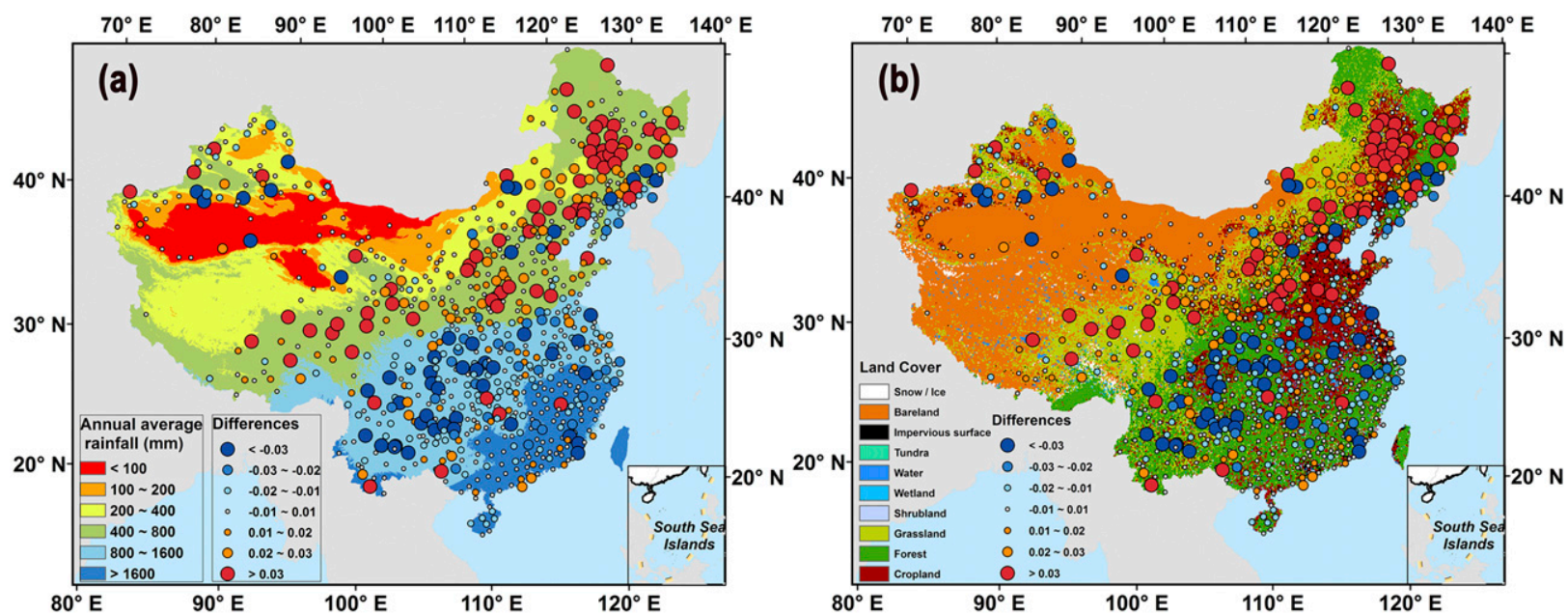

FIG. 14. As in Fig. 12a, but with a (a) mutiyear mean rainfall map and (b) land cover map as an external reference.

China. In addition, the evaluation of different PDSI suggested that PDSI-ET 0 performed well in northern China, especially in northeastern China, while PDSI$\mathrm{ET}_{p}$ performed well in southern China. Above results indicated the differences between PDSI-ET $\mathrm{P}_{0}$ and PDSI$\mathrm{ET}_{p}$ in many respects. Therefore, which form of PDSI should be chosen is crucial for drought quantification for a specific region. In this study, we found that the (a) PDSI-ET

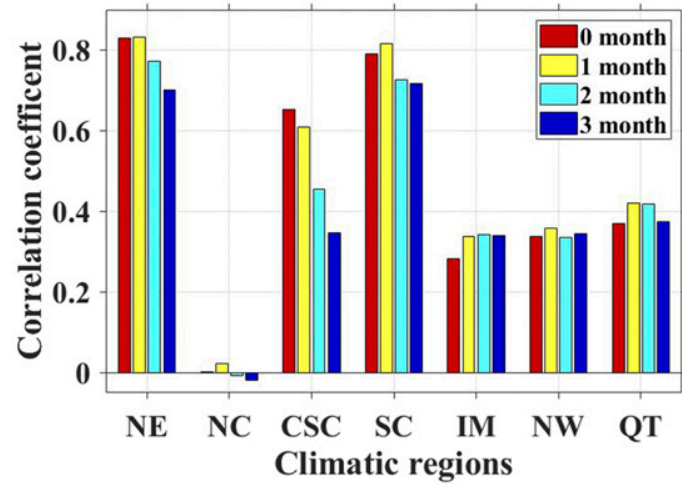

(c) PDSI-ET

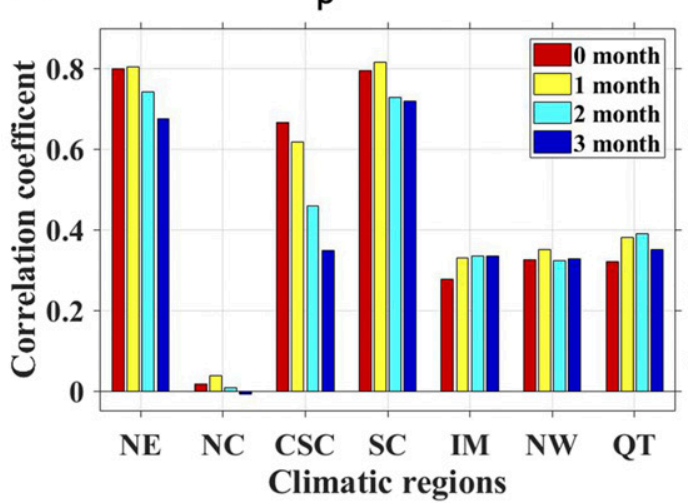

(b) scPDSI-ET

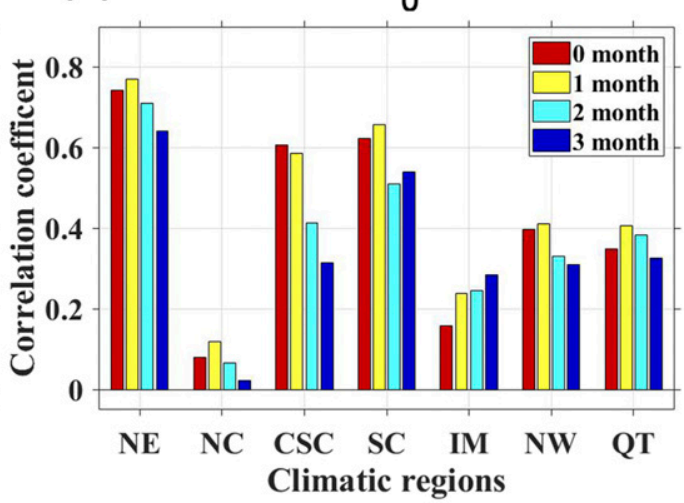

(d) scPDSI-ET

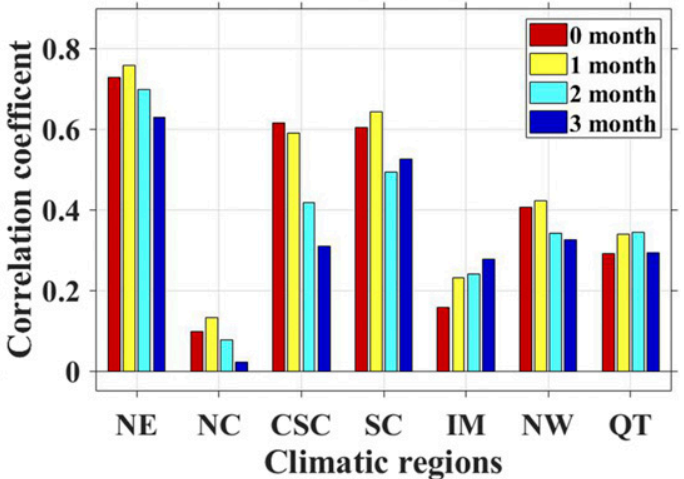

FIG. 15. Correlation coefficients between monthly (a) PDSI-ET 0 , (b) scPDSI-ET $_{0}$, (c) PDSI-ET , and (d) scPDSI$\mathrm{ET}_{p}$ and WSDI at different time lags in seven regions in China for the period 2003-13. 


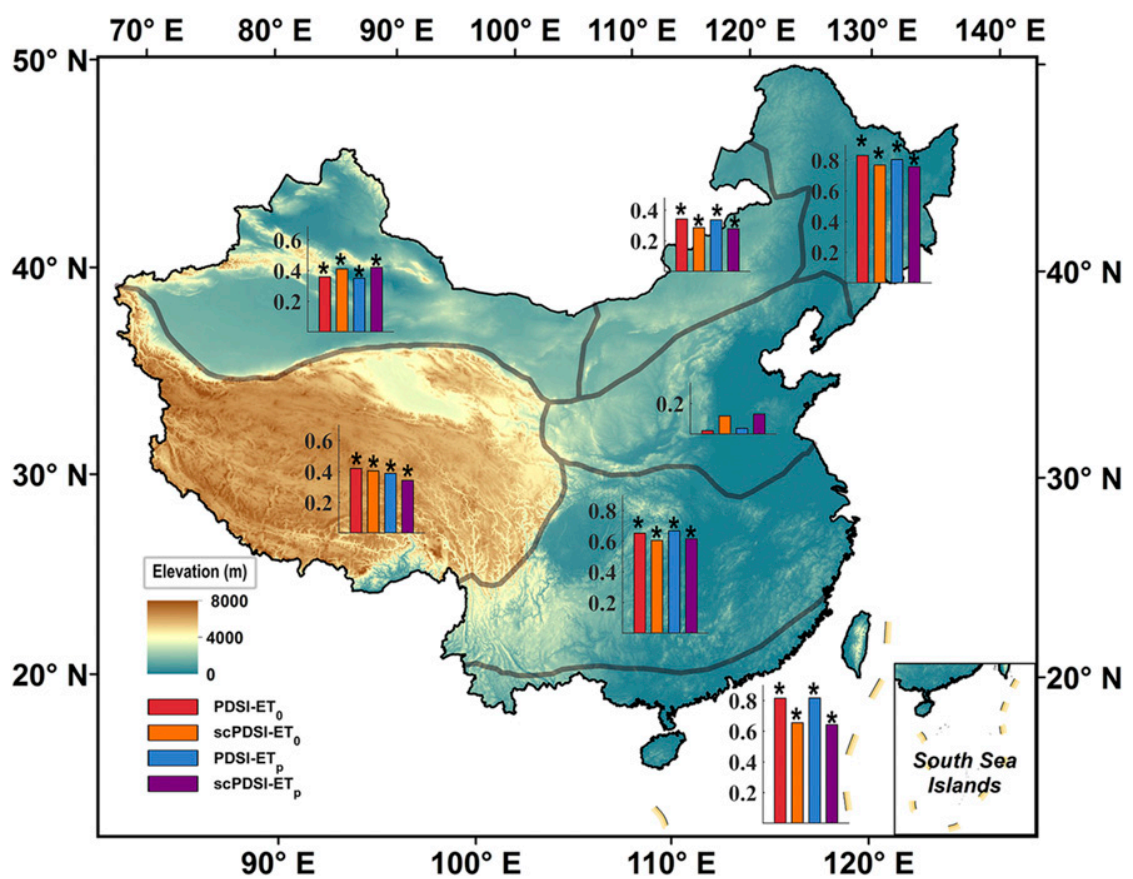

FIG. 16. Correlation coefficients between WSDI and different forms of PDSI in seven regions in China for the period 2003-13. Bars with an asterisk indicate $p<0.05$.

PDSI-ET ${ }_{0}$ performed well in the condition where the average rainfall is between about 350 and $750 \mathrm{~mm} \mathrm{yr}^{-1}$. The reason may be that the vegetation in these regions, namely the crop and grass (Fig. 14b), is close to the reference crop defined by $\mathrm{ET}_{0}$. The $\mathrm{PDSI}^{-E} \mathrm{~T}_{p}$ has a good performance in a larger scale because "a short green crop" defined by $\mathrm{ET}_{p}$ is more widely distributed than that defined by $\mathrm{ET}_{0}$.

In short, both the $\mathrm{ET}_{0}$ and $\mathrm{ET}_{p}$ equations have the merits and limitations. The above analysis highlights the necessity of a full consideration of the assumptions and ideal conditions included in different PET calculation methods before they are used to estimate atmospheric water demand.

\section{c. Comparison of PDSI and scPDSI}

In this study, we found the spatial comparability of scPDSI is better than that of PDSI, which is also reported by previous studies. For example, the modified scPDSI performed more consistently and allowed for more accurate determinations of drought conditions than the original PDSI at different locations in all climate zones in the conterminous United States (Wells et al. 2004). However, according to the evaluations of PDSI and scPDSI in this study, the original PDSI correlated more closely with NDVI anomalies, SMA and WSDI than did by scPDSI in most regions of China. One of the major reason is that scPDSI captured less severe meteorological droughts than PDSI. This may be due to 1$)$ the modifications to the scPDSI reduced the impact of using different PET methods (van der Schrier et al. 2011), which led to an insensitivity of scPDSI to changes in wet or dry conditions, and 2) the modifications to the self-calibration duration factors $(p$ and $q$ ) and the climatic characteristics $(K)$ potentially make the scPDSI more sensitive to the characteristics of datasets. According to a previous study in the Yellow River basin in northern China (Liu et al. 2016), the self-calibrating process further destabilized the drought identification performance of scPDSI among different datasets. This is not to deny the contributions of the self-calibrating procedure, which improves the spatial consistency of PDSI and controls the frequency of extreme events (Dai 2011b; Trenberth et al. 2014).

\section{d. The evaluation of PDSI}

In this study, the NDVI anomalies in northeastern China were not all well correlated to PDSI even though most of correlations are significant (if $R>0.2$ then $p<$ 0.01 ), which indicated that PDSI could not capture all the vegetative droughts. Meanwhile, all forms of PDSI did not show significant correlation with WSDI in NC, which is in line with the finding of M. Zhao et al. (2017) that suggested a drying trend indicated by GRACEbased terrestrial water storage while a wetting trend indicated by PDSI in this region. In addition, Qin et al.'s (2015) 

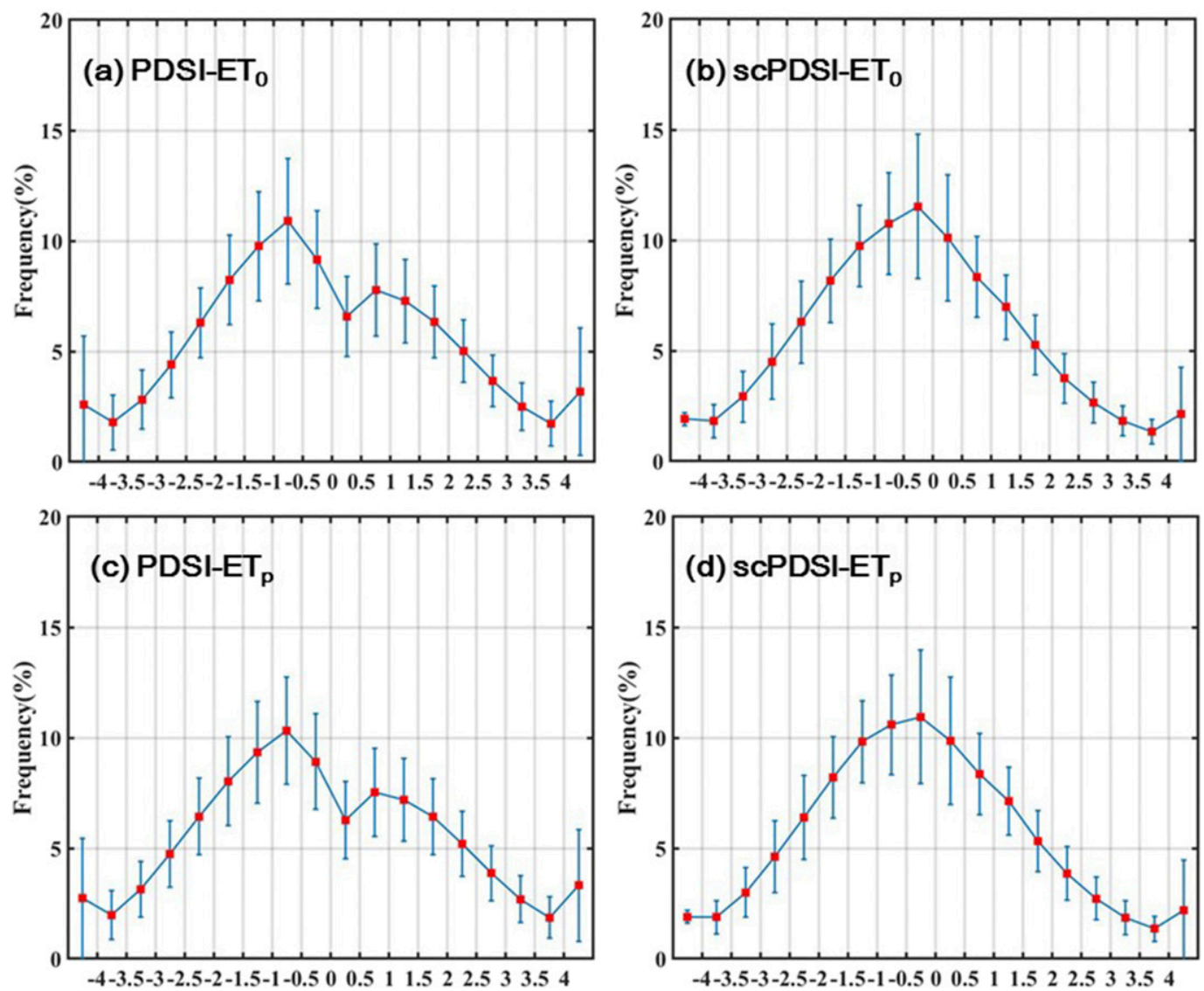

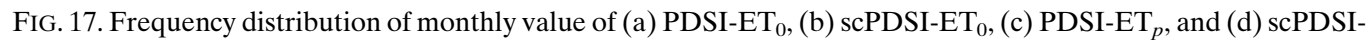
$\mathrm{ET}_{p}$ at all of the 755 stations in China for the period 1961-2013.

study in the same area found that NDVI and SMA increased during 2002-14 despite significantly decrease of annual precipitation. The agricultural irrigation associated groundwater pumping should be responsible for the low correlation between WSDI and PDSI in NC (Dai 2011a). In addition, the correlation coefficients between PDSI and SMA in some stations in NW and QT were relative low, because that not only the $\mathrm{P}$ or evapotranspiration but also the glacial and snowmelt from mountains (Barnett et al. 2005) participate in local water balance. The above analysis suggested that despite the PDSI is a good meteorological drought index, while it could not fully represent the changes of land water conditions.

\section{Conclusions}

In this study, the performances of four forms of PDSI, including the original PDSI based on either $\mathrm{ET}_{0}$ or $\mathrm{ET}_{p}$, the scPDSI based on either $\mathrm{ET}_{0}$ or $\mathrm{ET}_{p}$, respectively, were compared in China from 1961 to 2013. The primary conclusions are:
- For China as a whole, all four forms of PDSI suggested a wetting trend during the studied periods, with a relatively larger increasing trend suggested by PDSI-ET ${ }_{p}$ due to the faster decreasing rate of $E_{p}$. Regionally, widely distributed wetting trends were observed in Northwestern China due to the increasing precipitation, while the central and south-central China underwent drying trends from 1961 to 2013.

- Vegetation changes were more closely correlated with PDSI-ET $T_{0}$ than other forms of PDSI in the east of northern China. PDSI or scPDSI with $\mathrm{ET}_{0}$ had relative better performance in capturing changes in SMA and WSDI in northern China, especially in northeastern China, while PDSI or scPDSI with $\mathrm{ET}_{p}$ performed well in southern China.

- PDSI-ET 0 performed better than PDSI-ET $p$ over regions covered by grass and agricultural crops, where the annual mean precipitation is between about 350 and about $750 \mathrm{~mm} \mathrm{yr}^{-1}$. However, for those regions out of this precipitation scope, $\mathrm{PDSI}-\mathrm{ET}_{p}$ had a better performance than PDSI-ET . $_{0}$ 


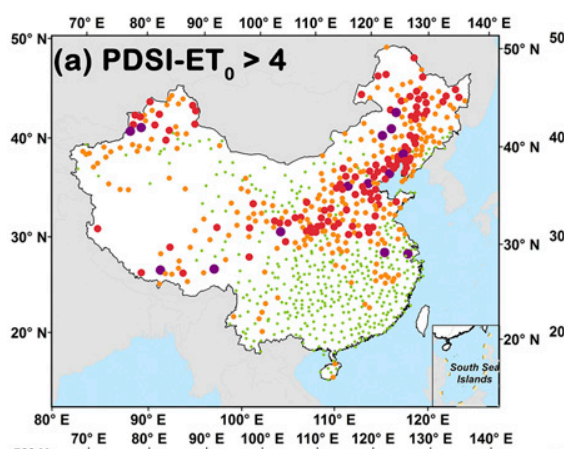

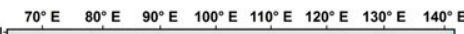

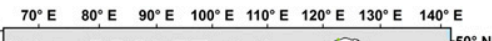

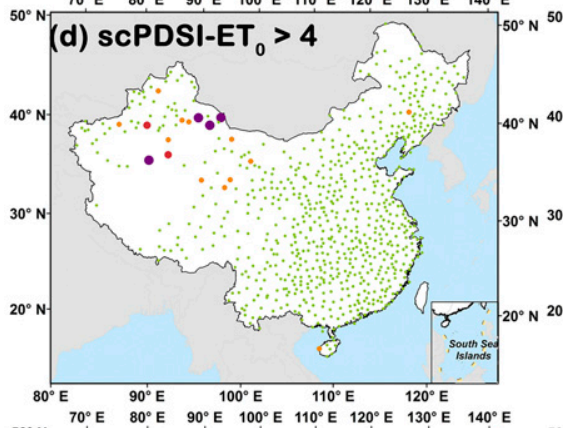

$50^{\circ} \mathrm{N} \quad 70^{\circ} \mathrm{E} \quad 80^{\circ} \mathrm{E} \quad 90^{\circ} \mathrm{E} \quad 100^{\circ} \mathrm{E} \quad 110^{\circ} \mathrm{E} \quad 120^{\circ} \mathrm{E} \quad 130^{\circ} \mathrm{E} \quad 140^{\circ} \mathrm{E}$
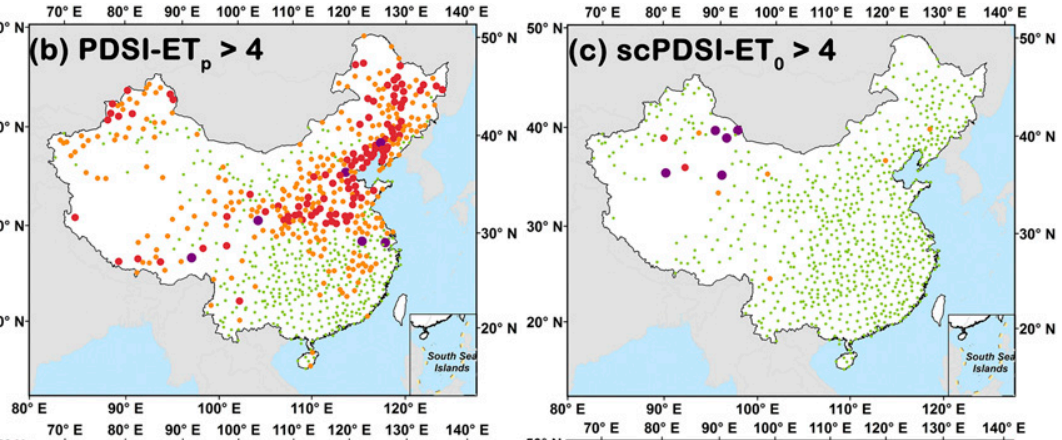

(e) PDSI-ET $<-4$
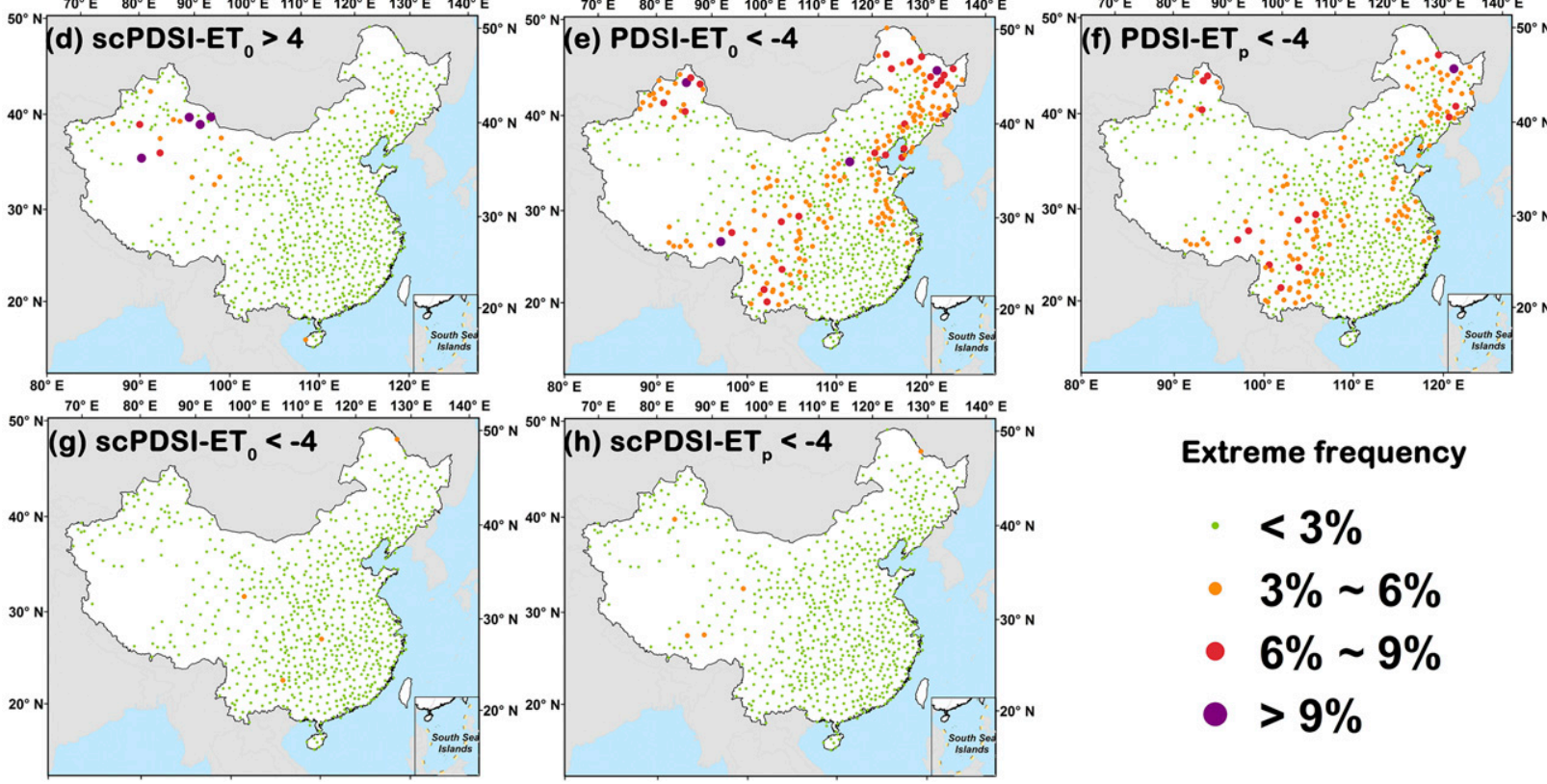

Extreme frequency

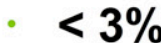

- $3 \% \sim 6 \%$

- $6 \% \sim 9 \%$

- $>9 \%$

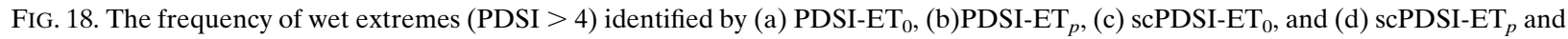
dry extremes (PDSI < -4) identified by (e) PDSI-ET ${ }_{0}$, (f)PDSI-ET ${ }_{p},(\mathrm{~g})$ scPDSI-ET $_{0}$, and (h) scPDSI-ET .

- The spatial comparability of scPDSI was better than that of PDSI, while the PDSI correlated more closely with NDVI anomalies, SMA, and WSDI than did scPDSI in most regions of China.

Acknowledgments. This work is financially supported by the National Key Research and Development Program of China (Grants 2017YFA0603601 and 2016YFC0500805), the Strategic Priority Research Program of Chinese Academy of Sciences (Grant XDA20060402) and the National Natural Science Foundation of China (Grants 41101074 and 41671083).

\section{REFERENCES}

Akinremi, O. O., S. M. Mcginn, and A. G. Barr, 1996: Evaluation of the Palmer drought index on the Canadian Prairies. J. Climate, 9, 897-905, https://doi.org/10.1175/1520-0442(1996)009<0897: EOTPDI $>2.0 . \mathrm{CO} ; 2$.
Allen, R. G., L. S. Pereira, D. Raes, and M. Smith, 1998: Crop evapotranspiration: Guidelines for computing crop water requirements. FAO Irrigation and Drainage Paper 56, 300 pp., http://www.fao.org/3/X0490E/X0490E00.htm.

Alley, W. M., 1984: The Palmer drought severity index: Limitations and assumptions. J. Climate Appl. Meteor., 23, 1100-1109, https://doi.org/10.1175/1520-0450(1984)023<1100:TPDSIL > 2.0.CO;2.

Barnett, T. P., J. C. Adam, and D. P. Lettenmaier, 2005: Potential impacts of a warming climate on water availability in snowdominated regions. Nature, 438, 303-309, https://doi.org/ 10.1038/nature04141.

Chen, H., and J. Sun, 2015: Changes in drought characteristics over China using the standardized precipitation evapotranspiration index. J. Climate, 28, 5430-5447, https://doi.org/10.1175/ JCLI-D-14-00707.1.

Chu, C., J. Zhao, and C. An, 2015: Climate changes in different climate zones in central China and their relationship with ENSO from 1957 to 2011 (in Chinese). Areal Res. Dev., 34 (5), 121-127.

Dai, A., 2011a: Characteristics and trends in various forms of the Palmer Drought Severity Index during 1900-2008. J. Geophys. Res., 116, D12115, https://doi.org/10.1029/2010JD015541. 
— 2011b: Erratum: Drought under global warming: A review. Wiley Interdiscip. Rev.: Climate Change, 2, 45-65, https:// doi.org/10.1002/wcc.81.

— K. E. Trenberth, and T. Qian, 2004: A global dataset of Palmer drought severity index for 1870-2002: Relationship with soil moisture and effects of surface warming. J. Hydrometeor., 5, 1117-1130, https://doi.org/10.1175/JHM-386.1.

Dodds, P. E., W. S. Meyer, and A. Barton, 2005: Review of methods to estimate irrigated reference crop evapotranspiration across Australia. CRC for Irrigation Futures Tech. Rep. No 04/05, 48 pp., https://publications.csiro.au/rpr/pub? list $=$ BRO\&pid $=$ procite $: 8177 \mathrm{~b} 7 \mathrm{f4}-9950-4 \mathrm{e} 57-8458-\mathrm{f338d0e5c047.}$

Hao, Y., S. Q. Wang, H. Q. Lu, Q. Yu, Z. C. Zhu, R. B. Myneni, L. Qiang, and H. H. Shugart, 2015: Development of a remotely sensing seasonal vegetation-based Palmer Drought Severity Index and its application of global drought monitoring over 1982-2011. J. Geophys. Res. Atmos., 119, 9419-9440, https:// doi.org/10.1002/2014JD021673.

Hobbins, M., A. Dai, M. Roderick, and G. Farquhar, 2008: Revisiting potential evapotranspiration parameterizations as drivers of long-term water balance trends. Geophys. Res. Lett., 35, L12403, https://doi.org/10.1029/2008GL033840.

Hua, T., X. Wang, C. Zhang, L. Lang, and H. Li, 2017: Responses of vegetation activity to drought in northern China. Land Degrad. Dev., 28, 1913-1921, https://doi.org/10.1002/ldr.2709.

Jacobi, J., D. Perrone, L. L. Duncan, and G. Hornberger, 2013: A tool for calculating the Palmer drought indices. Water Resour. Res., 49, 6086-6089, https://doi.org/10.1002/wrcr.20342.

Kendall, M. G., 1948: Rank Correlation Methods. Charles Griffin, $160 \mathrm{pp}$.

Li, B., Y. Chen, Z. Chen, and W. Li, 2012: Trends in runoff versus climate change in typical rivers in the arid region of northwest China. Quat. Int., 282, 87-95, https://doi.org/10.1016/ j.quaint.2012.06.005.

_ _ _ X. X. Shi, Z. Chen, and W. Li, 2013: Temperature and precipitation changes in different environments in the arid region of northwest China. Theor. Appl. Climatol., 112, 589-596, https://doi.org/10.1007/s00704-012-0753-4.

Liu, M., Y. Shen, Y. Zeng, and C. Liu, 2010: Trend in pan evaporation and its attribution over the past 50 years in China. J. Geogr. Sci., 20, 557-568, https://doi.org/10.1007/s11442-0100557-3.

Liu, X., Y. Luo, D. Zhang, M. Zhang, and C. Liu, 2011: Recent changes in pan-evaporation dynamics in China. Geophys. Res. Lett., 38, L13404, https://doi.org/10.1029/2011GL047929.

Liu, Y., L. Ren, Y. Hong, Y. Zhu, X. Yang, F. Yuan, and S. Jiang, 2016: Sensitivity analysis of standardization procedures in drought indices to varied input data selections. J. Hydrol., 538, 817-830, https://doi.org/10.1016/j.jhydrol.2016.04.073.

— , Y. Zhu, L. Ren, V. P. Singh, X. Yang, and F. Yuan, 2017: A multiscalar Palmer drought severity index. Geophys. Res. Lett., 44, 6850-6858, https://doi.org/10.1002/2017GL073871.

Long, D., B. R. Scanlon, L. Longuevergne, A. Y. Sun, D. N. Fernando, and H. Save, 2013: GRACE satellite monitoring of large depletion in water storage in response to the 2011 drought in Texas. Geophys. Res. Lett., 40, 3395-3401, https:// doi.org/10.1002/grl.50655.

Mann, H. B., 1945: Nonparametric tests against trend. Econometrica, 13, 245-259, https://doi.org/10.2307/1907187.

McKee, T. B., N. J. Doesken, and J. Kleist, 1993: The relationship of drought frequency and duration to time scales. 8th Conf. on Applied Climatology, Anaheim, CA, Amer. Meteor. Soc., 179-184.
McVicar, T., L. Li, T. Van Niel, M. Hutchinson, X. Mu, and Z. Liu, 2005: Spatially distributing 21 years of monthly hydrometeorological data in China: Spatio-temporal analysis of FAO-56 crop reference evapotranspiration and pan evaporation in the context of climate change. CSIRO Land and Water Technical Report 8/05, 316 pp., https://doi.org/10.4225/08/ $585 \mathrm{ac} 38172 \mathrm{fb} 7$.

, and Coauthors, 2012: Global review and synthesis of trends in observed terrestrial near-surface wind speeds: Implications for evaporation. J. Hydrol., 416-417, 182-205, https://doi.org/ 10.1016/j.jhydrol.2011.10.024.

Nachtergaele, F., and Coauthors, 2010: The Harmonized World Soil Database. Proc. 19th World Congress of Soil Science, Brisbane, Australia, International Union of Soil Sciences, 34-37, https:// www.iuss.org/19th\%20WCSS/Symposium/pdf/2330.pdf.

Palmer, W. C., 1965: Meteorological drought. U.S. Weather Bureau Research Paper 45, 58 pp., http://www.ncdc.noaa.gov/ temp-and-precip/drought/docs/palmer.pdf.

Penman, H. L., 1948: Natural evaporation from open water, bare soil and grass. Proc. Roy. Soc. London, 193A, 120-145, https:// doi.org/10.1098/rspa.1948.0037.

_ 1963: Vegetation and hydrology. Commonwealth Bureau of Soils Tech. Comm. 53, Commonwealth Agricultural Bureaux, 124 pp.

Qin, Y., D. Yang, H. Lei, X. Kai, and X. Xu, 2015: Comparative analysis of drought based on precipitation and soil moisture indices in Haihe basin of North China during the period of 1960-2010. J. Hydrol., 526, 55-67, https://doi.org/10.1016/ j.jhydrol.2014.09.068.

Roderick, M. L., L. D. Rotstayn, G. D. Farquhar, and M. T. Hobbins, 2007: On the attribution of changing pan evaporation. Geophys. Res. Lett., 34, L17403, https://doi.org/10.1029/ 2007 GL031166.

Schrier, G. V. D., K. R. Briffa, P. D. Jones, and T. J. Osborn, 2006: Summer moisture variability across Europe. J. Climate, 19, 1013-1017, https://doi.org/10.1175/JCLI3734.1.

Sheffield, J., E. F. Wood, and M. L. Roderick, 2012: Little change in global drought over the past 60 years. Nature, 491, 435-438, https://doi.org/10.1038/nature11575.

Shuttleworth, W., 1993: Evaporation. Handbook of Hydrology, D. R. Maidment, Ed. McGraw-Hill, 4.1-4.53.

Sinha, D., T. H. Syed, J. S. Famiglietti, J. T. Reager, and R. C. Thomas, 2017: Characterizing drought in India using GRACE observations of terrestrial water storage deficit. J. Hydrometeor., 18, 381-396, https://doi.org/10.1175/ JHM-D-16-0047.1.

Thornthwaite, C. W., 1948: An approach toward a rational classification of climate. Geogr. Rev., 38, 55-94, https://doi.org/ 10.2307/210739.

Trenberth, K. E., A. Dai, G. V. D. Schrier, P. D. Jones, J. Barichivich, K. R. Briffa, and J. Sheffield, 2014: Global warming and changes in drought. Nat. Climate Change, $\mathbf{4}$ 17-22, https://doi.org/10.1038/nclimate2067.

Valiantzas, J. D., 2013: Simplified forms for the standardized FAO-56 Penman-Monteith reference evapotranspiration using limited weather data. J. Hydrol., 505, 13-23, https:// doi.org/10.1016/j.jhydrol.2013.09.005.

van der Schrier, G., K. R. Briffa, T. J. Osborn, and E. R. Cook, 2006: Summer moisture availability across North America. J. Geophys. Res., 111, D11102, https://doi.org/10.1029/ 2005JD006745.

_ - P. Jones, and K. Briffa, 2011: The sensitivity of the PDSI to the Thornthwaite and Penman-Monteith parameterizations 
for potential evapotranspiration. J. Geophys. Res., 116, D03106, https://doi.org/10.1029/2010JD015001.

Vicenteserrano, S. M., S. Beguería, J. I. Lópezmoreno, M. Angulo, and A. E. Kenawy, 2010: A new global $0.5^{\circ}$ gridded dataset (1901-2006) of a multiscalar drought index: Comparison with current drought index datasets based on the Palmer drought severity index. J. Hydrometeor., 11, 1033-1043, https://doi.org/ 10.1175/2010JHM1224.1.

_ - and Coauthors, 2013: Response of vegetation to drought time-scales across global land biomes. Proc. Natl. Acad. Sci. USA, 110, 52-57, https://doi.org/10.1073/pnas.1207068110.

—_, and Coauthors, 2014: Evidence of increasing drought severity caused by temperature rise in southern Europe. Environ. Res. Lett., 9, 044001, https://doi.org/10.1088/1748-9326/9/4/044001.

Wang, W., Y. Zhu, R. Xu, and J. Liu, 2015: Drought severity change in China during 1961-2012 indicated by SPI and SPEI. Nat. Hazards, 75, 2437-2451, https://doi.org/10.1007/s11069-014-1436-5.

Wang, Z., J. Li, C. Lai, Z. Zeng, R. Zhong, X. Chen, X. Zhou, and M. Wang, 2017: Does drought in China show a significant decreasing trend from 1961 to 2009? Sci. Total Environ., 579, 314-324, https://doi.org/10.1016/j.scitotenv.2016.11.098.

Wells, N., S. Goddard, and M. J. Hayes, 2004: A self-calibrating Palmer drought severity index. J. Climate, 17, 2335-2351, https://doi.org/ 10.1175/1520-0442(2004)017<2335:ASPDSI > 2.0.CO;2.

Wu, X., Z. Wang, X. Zhou, C. Lai, W. Lin, and X. Chen, 2016: Observed changes in precipitation extremes across 11 basins in China during 1961-2013. Int. J. Climatol., 36, 2866-2885, https://doi.org/10.1002/joc.4524.

Xu, C.-Y., L. Gong, T. Jiang, D. Chen, and V. Singh, 2006: Analysis of spatial distribution and temporal trend of reference evapotranspiration and pan evaporation in Changjiang (Yangtze River) catchment. J. Hydrol., 327, 81-93, https:// doi.org/10.1016/j.jhydrol.2005.11.029.
Yin, Y., S. Wu, D. Zheng, and Q. Yang, 2008: Radiation calibration of FAO56 Penman-Monteith model to estimate reference crop evapotranspiration in China. Agric. Water Manage., 95, 77-84, https://doi.org/10.1016/j.agwat.2007.09.002.

Yu, M., Q. Li, M. J. Hayes, M. D. Svoboda, and R. R. Heim, 2014: Are droughts becoming more frequent or severe in China based on the Standardized Precipitation Evapotranspiration Index: 1951-2010? Int. J. Climatol., 34, 545-558, https:// doi.org/10.1002/joc.3701.

Zhang, D., Q. Zhang, A. D. Werner, and X. Liu, 2016: GRACEbased hydrological drought evaluation of the Yangtze River basin, China. J. Hydrometeor., 17, 811-828, https://doi.org/ 10.1175/JHM-D-15-0084.1.

Zhang, J., F. Sun, J. Xu, Y. Chen, Y. F. Sang, and C. Liu, 2016: Dependence of trends in and sensitivity of drought over China (1961-2013) on potential evaporation model. Geophys. Res. Lett., 43, 206-213, https://doi.org/10.1002/2015GL067473.

Zhang, Q., T. Qi, J. Li, V. P. Singh, and Z. Wang, 2015: Spatiotemporal variations of pan evaporation in China during 1960-2005: Changing patterns and causes. Int. J. Climatol., 35, 903-912, https://doi.org/10.1002/joc.4025.

Zhao, H., G. Gao, W. An, X. Zou, H. Li, and M. Hou, 2017: Timescale differences between SC-PDSI and SPEI for drought monitoring in China. Phys. Chem. Earth, 102, 48-58, https://doi.org/10.1016/j.pce.2015.10.022.

Zhao, M., G. A, I. Velicogna, and J. S. Kimball, 2017: A global gridded dataset of GRACE drought severity index for 2002-14: Comparison with PDSI and SPEI and a case study of the Australia Millennium Drought. J. Hydrometeor., 18, 2117-2129, https://doi.org/10.1175/JHM-D-16-0182.1.

Zhao, S. Q., 1983: A new scheme for comprehensive physical regionalization in China. Acta Geogr. Sin., 50, 1-10, https:// doi.org/10.11821/xb198301001. 